\title{
THE FACT OF THE APPLICATION OF REQUIREMENTS FOR PEOPLE WITH DISABILITIES ON THE NEWLY CONSTRUCTED COLLEGE BUILDINGS AT KING SAUD UNIVERSITY
}

\section{Ibrahim R. S. Aljowair}

Associate professor - Department of Architecture and building science College of Architecture, King Saud University

(Received July 7, 2010 Accepted November 9, 2010)

King Saud University (KSU) is considered to be one of the largest universities in Saudi Arabia in term of number of students. Persons with disabilities could almost found in each building of the campus. Despite of the fact that the Royal Declaration - issued since two decades ago - that stresses on facilitate all buildings for the easy use of persons with disabilities, and the fact that the Ministry of Rural and Municipal Affairs has published a regulation booklet indicates services should be included; most of the buildings within the campus aren't suited for persons with disabilities.

The aim of this study is to explore and inspect the application of these standards and requirements. The methodology depends on choosing a sample of newly constructed buildings at KSU campus. A field survey has been conducted to collect data and take photos of provided services to determine its existence and compliance with general and specific requirements set forth in the ministry booklet.

The study proved invalidity of the hypothesis that the newly constructed buildings within the university campus designed by famous architects Saudis or non-Saudi and approved by the university agency for construction and projects apply the requirements and technical standards for the disabled and people with special needs.

It was found that some elements of public and private requirements for disabled, such as external signage, and parking are not available. While, other elements such as slopes, interior signage, and toilets are either partial provided or incomplete or its dimensions doesn't comply with the requirements.

The lack of awareness of the needs of persons with disabilities is not limited to ordinary people but also include the renowned architects. The Vice Rectorate for Projects bears main responsibility for the absence of such services and deficiencies in the application of the requirements for the disabled. Mean while, consulting firms that designed such buildings bear part of responsibility too.

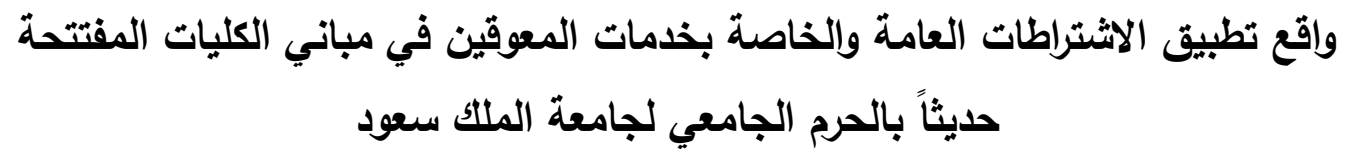

$$
\begin{aligned}
& \text { د. إبراهيم بن راشد سعد الجوير } \\
& \text { أستاذ مشارك بقسم العمارة وعلوم البناء - كلية العمارة والتخطيط - جامعة الملك سعود - الرياض. }
\end{aligned}
$$




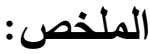

تُعد جامعة الملك سعود من الجامعات التي تحتضن أكبر عدد من الطلاب بالمملكة، حيث يكاد لا يخلو مبنى واحد من عشرات المستخدمين من ذوي الاحتياجات الخاصة. بالرغم من مرور أكثر من عقدين من الزمن على الكى التعميم السامي الكريم الذي يحث على مراعاة تيسير الخدمات للمعوقين، وملاحظة ذلك عند تصميم وتجهيز المباني الني يتعامل معها الجمهور، وبالرغم من إصدار وزارة الثُؤون البلدية والقروية كتيب الاثتراطات العامة

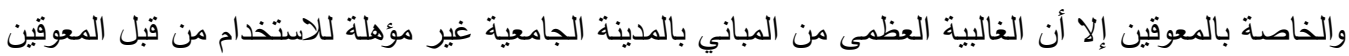
وذوي الاحتياجات الخاصة.

وهدف هذا البحث معرفة واقع تطبيق الاشتراطات والمعايير في عينة من مباني الكليات الني صمدت وشيدت وافتتحت حديثاً. أعتمد الباحث في جمع المعلومات على الزيارات والمسح الميداني والتصوير الفوتوغرافي للمباني في فئي لمعرفة مدى وجود الاثتراطات العامة والخاصة المنصوص عليها في كتيب الوزارة. ولقد ثبت عدم صحة الفرضية المنتشرة بين المعماريين وطلاب العمارة والمتقفين والقائلة "إن مباني الكليات المفتحة حديثاً بالددينة الجامعية لجامعة الملك سعود والمصممة من قبل معماريين مشهورين سعوديين أو غير سعوديين والمراجعة والمعتمدة من وكالة الجامعة للمشاريع؛ هي في الغالب شاملة الاشتراطات والمعايير الفنية الخاصة بالمعوقين وذوي الاحتياجات الخاصة". لقد وجد أن بعض عناصر الاشتراطات العامة والخاصة، متل: اللوحات الإرشادية الخارجية، ومواقف السيارات؛ غير موجودة على الإطلاق، بينما العناصر الأخرى، مثل: المنحدرات، واللوحات الإرشادية الداخلية،

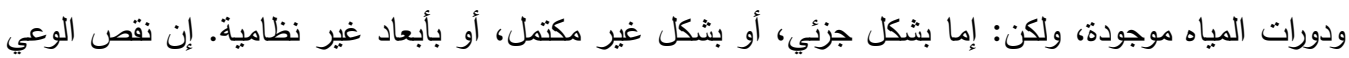
باحتياجات المعوقين ليس مقصوراً على البسطاء من الناس بل بشمل الدعماريين والمهندسين المعماريين ممن الئن غطت شهرتهم أنحاء المعورة. وتقع المسؤولية في عدم وجود تلك الخدمات على وكالة الجامعة للمشاريع (إدارة المشاريع سابقاً) إلى حد كبير ، وإن كانت المكاتب المصمدة لتلك المباني تتحمل جزءواً من المسؤولية.

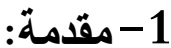

قدمت حكومة المملكة العربية السعودية ممثلة في وزارة العمل والثؤون الاجتماعية - ولازالت - تقام الدعم المادي والمعنوي للمعوقين عن طريق إعانات مالية سنوية تقام لأسرهم أو عن طريق مؤسسات رعاية الأطفال الهشلولين أو المراكز المختلفة مثل: مراكز التأهيل المهني الثامل أو مراكز التأهيل الاجتماعي أو مراكز التأهيل

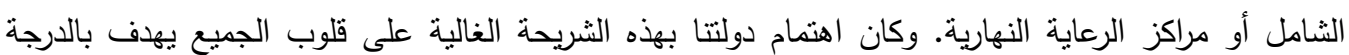

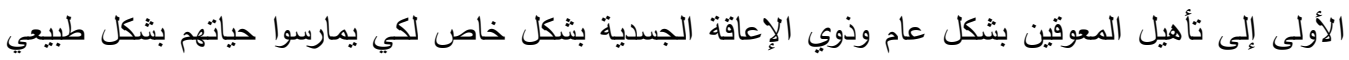
كالآخرين [1]].

هذه الرعاية تبعها إصدار الدقام السامي للتعميم رقم 14/7/14203هـ في 1402/1/21هـ للجهات الحكومية كافة ينص على: " ضرورة مراعاة تيسير الخدمات للمعوقين، وملاحظة ذللك عند تصميم وتجهيز المباني التي

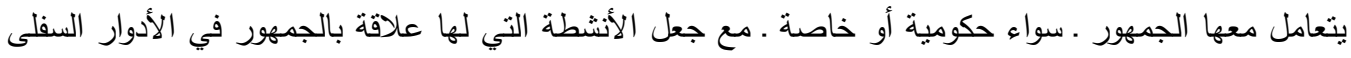


قدر الإمكان، على أن يتولى موظف يكون مقره عند مدخل المبنى تخليص خدمات المواطن المعوق وتيسير

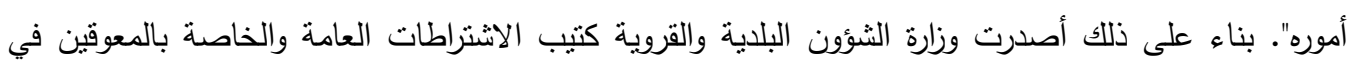
رجب 1412هـ لأخذها في الحسبان عند الثروع في أعمال التصميم أو الترميم بهدف تيسير وتسهيل حركة المعوق وتهيئة الأوضاع والأبعاد والفراغات المناسبة له في الأماكن التي يرتادها [2].

حسب الإحصاءات العالمية نسبة الإعاقة في العالم تصل إلى قرابة 10\% من تعداد الناس على هذه المعمورة حيث تقل في الدول الصناعية وتزيد في الدول النامية. هذه الفئة العزيزة على قلوبنا جميعاً من ذوي الإعاقة

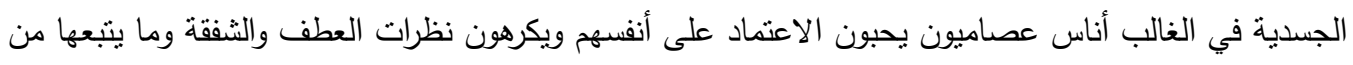
رغبة في المساعدة. يود المعوقون في الغالب أن يمارسوا حياتهم مثل غيرهم فهم يحبون أن بذهبوا إلى المسجد والمدرسة والعمل والسوق والملعب والحديقة ..إلخ، معتمدين فقط على أنفسهم. كيف لهم بذللك في مجتمع غالبية أفراده لازالوا ينظرون إليهم بعطف وخوف مفرط ويتوقعون منهم أن يمكثرا طوال حياتهم بين جدران غرفهم يعايشون الظلمة والوحدة والعجز ينتظرون المساعدة. وغالبية أسر المعوقين جسدياً لا نوفر لهم سبل الاعتماد على أنفسهر من منطلق الخوف عليهم.

الآن وبعد مرور أكثر من عقدين من الزمن على التعميم السامي الكريم هل تغير شيء؟ قد لا يكون غريباً عندما نجد مبنىً صغيراً - عاماً كان أو خاصاً - غير مؤهل لاستخدام المعوقين جسدياً، ولكن ماذا تكون ردة الفعل عندما يكون المبنى مثلاً: كلية العمارة والتخطيط وفي جامعة تعد من كبريات الجامعات في العالم العربي والإسلامي أكاديمياً ومعمارياً، وقد كلف تشييدها عشرات الملايين من الريالات، ولكن مبناها غير مؤهل لاستخدام المعوقين جسدياً:

\section{2- 2 الإعـاقة}

الإعاقة يمكن تعريفها أنها أي قصور جزئي أو كامل في قدرات الفرد الجسمانية أو العقلية أو الحسية يؤثز عليه في العيش بصورة طبيعية. والإعاقة تتقسم إلى: الإعاقة الجسدية (التي تركز عليها الدراسة لكونها المعنية بكتيب الاشتراطات).

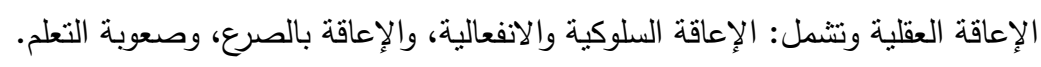
الإعاقة الحسية وتشمل: الإعاقة الكلامية، والإعاقة السمعية، والإعاقة البصرية.

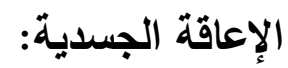

المملكة ليس بها إحصائية كاملة، فطبقاً للاراسة التي قام بها الدكتور محسن بن علي الحازمي عن الإعاقة

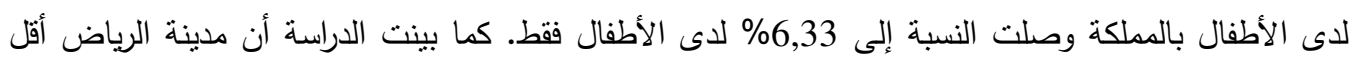
المدن على مستوى المملكة حيث وصلت النسبة إلى 4,36\% لاى الأطفال فقط. والإعاقة الجسدية لدى الأطفال بالرياض 3\% فقط من الأطفال المعوقين. هذه النسبة المنخفضة بالرياض تعود إلى عدة أسباب منها الحياة 
الاجتماعية والاقتصادية وما تثهده الرياض من تطور في الطب وما يصاحبه من افتتاح للمستثفيات وما ينتج

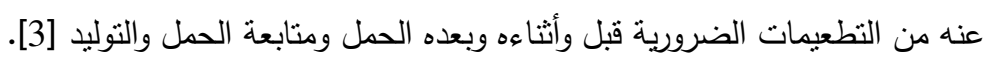

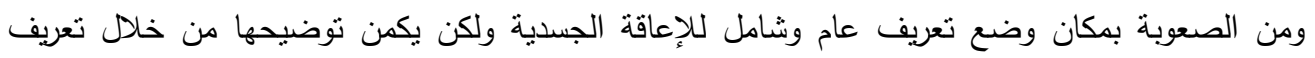

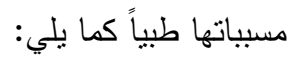

الثلل المخي: وهو ضعف أو نقص في القدرة على التحكم بالعضلات غير الإرادية للجسم.

الضمور العضلي: وهو ضعف تدريجي في العضلات ينطور لفقدان القدرة على المشي.

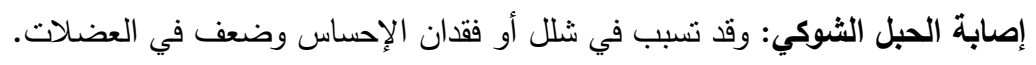

هشاثة العظام: وهو قصور في نمو العظام لدى الفرد يؤدي إلى كسرها.

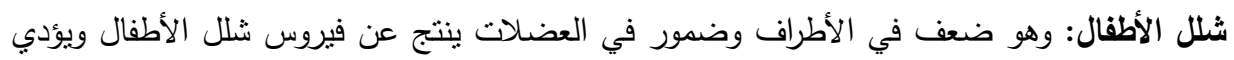
إلى شلل طرف في الجسم أو أكثر.

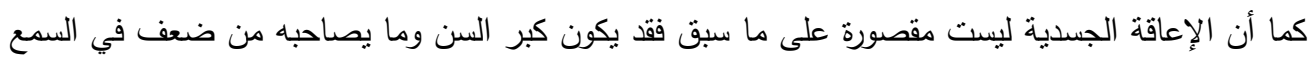

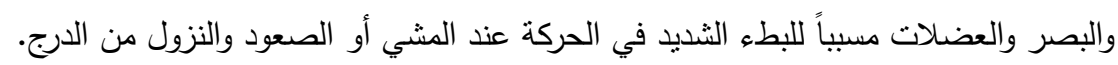

\section{3- 3 - 3تبب الاشتراطات:}

هذا الكتيب يشمل الاثتراطات والمعايير الفنية الواجب توفرها في المباني العامة والخاصة بالمملكة حيث نم

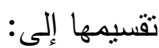

1. الاثتراطات العامة: المنحدرات، ومواقف السيارات، وممررات المشاة والأرصفة، ودورات المياه والحمامات.

2. الاشتراطات الخاصة: الدرابزينات والحواجز ، واللوحات واللافتات، والسلالم، والأبواب، والنوافذ، والطرقات

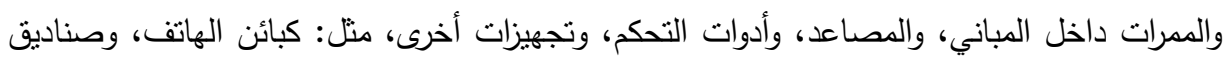
البريد، ومصادر مياه الثرب، وصناديق النفايات، واعتبارات تؤخذ عند تصميم المساجد.

وسيتم التركيز في هذا البحث على الاشتراطات الأكثر أهية والتي يحتاج إليها المعوق وذو الاحتياجات

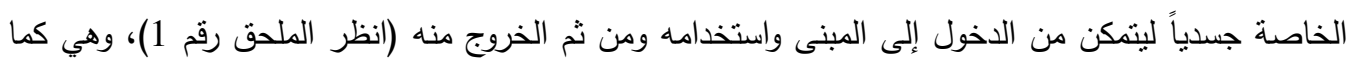

الاشتراطات العامة: المنحدرات، ومواقف السيارات، وممررات المشاة والأرصفة، ودورات المباه والحمامات.

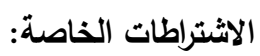

اللوحات الإرشادية الخارجية المتعلقة بمواقف السبارات، والمنحدرات والأرصفة الخارجية.

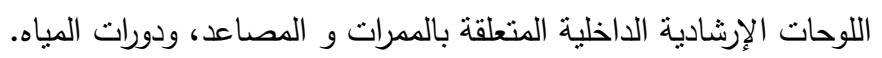

الممرات الداخلية.

المصاعد 
4- أهمية البحث:

تتركز من خلال المطالبة المستمرة في تطبيق الاشتراطات العامة والخاصة بالمعوقين وذوي الاحتياجات

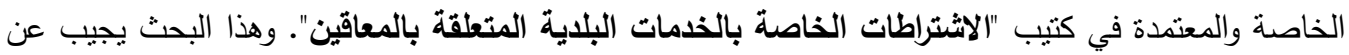
مدى تأهيل مباني الكليات المفتتحة للاراسة حديثاً بجامعة الملك سعود والتي تُعد من ضمن مساهمات الدولة للنهوض بالعملية التعليمية بالمملكة. هذه المباني ستعطي مؤشراً حقيقياً لمدى الجدية في تأهيل مباني المدينة الجامعية لاستخدام هذه الشريحة الغالية من منسوبيها.

\section{5- 5 أهداف البحث:}

يركز البحث على أهمية دراسة إمكانيات الحركة والوصول والاستعمال، وهي أهم المعايير المطلوب تحديدها أثتاء مرحلة التخطيط والتصميم، بهدف نتجيع هذه الفئة من الأشخاص المعوقين وذوي الاحتباجات الخاصة على ولى ولى الفي الحياة الثخصية ومحاولة الاندماج في مجتمع الجامعة، وتأمين بيئة متتاسبة مع احتياجاتهم المختلفة، وفق هنق متطلبات معايير مستقبل البيئة المبنية المستدامة التي أقرتها المؤسسات الدولية.

كما يتضمن البحث وصفاً لمجموعة العوائق التي نواجه الأشخاص المعوقين وذوي الاحتياجات الخاصة، والتي تحد من حركتهم وانتقالهم في البيئة الخارجية والداخلية لمباني الحديثة بالجامعة، ومتطلبات تخفيف هذه الحواجز المرتبطة بمتطلبات حركة المعوقين والتي تشجعهم على الحركة والانتقال ضمن المعايير التخطيطية والتصميمية المحدة في كتيب "الاشتراطات الخاصة بالخدمات البلاية المتعلقة بالمعاقين"، والذي تعتمد عليه هذه الدراسة.

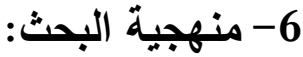

يوجد فرضية منذاولة بكثرة بين المعماريين وطلاب العمارة والمثقفين تقول: إن مباني المدينة الجامعية بجامعة الملك سعود والمصممة من قبل معماريين مشهورين سعوديين أو غير سعوديين والمراجعة والمعتمدة من وكالة الجامعة للمشاريع؛ تكون في الغالب شاملة لكل شيء بما في ذلك مراعاة الاشتراطات الخاصة بالمعوقين وذوي الاحتياجات الخاصة المنصوص عليها في كتيب "الاشتراطات الخاصة بالخدمات البلاية المتعلقة بالمعاقين". وهذا البحث يهدف إلى إثبات مدى صحة الفرضية أعلاه من عدمها وذللك من خلال: أولاً: القيام بزيارات ميدانية لمباني أربع كليات صممت وشيدت وافتتحت خلال السنوات العشر الماضية، وذلك للقيام بأعمال المسح الميداني باستخدام استبانة بحثية لرفع ما هو موجود في أرض الواقع ومقارنته بما هو موجود في كتيب وزارة الثؤون البلدية والقروية (انظر الملحق رقم 1). ثانياً: القيام بالتصوير الفوتوغرافي اللازم لعناصر المبنى التي تخدم البحث. 
إن معظم المباني في مدننا ومحافظاتتا ومراكزنا وقرانا غير مؤهلة لاستخدام المعوقين حركياً وفقاً للاراسة

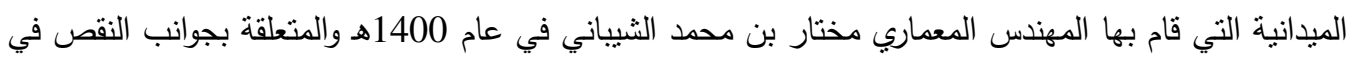

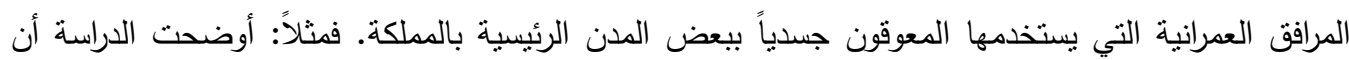

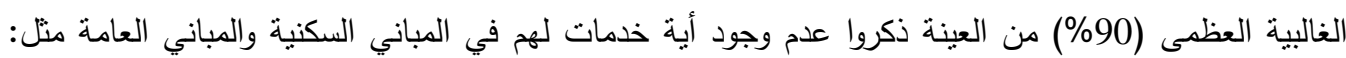

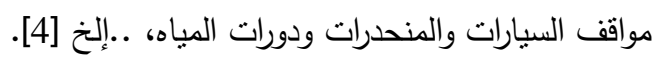
وعندما ينم التحدث عن تأمين الخدمات البلدية للمعوقين وذوي الاحتباجات الخاصة لابد من التعرف إلى ميثاق

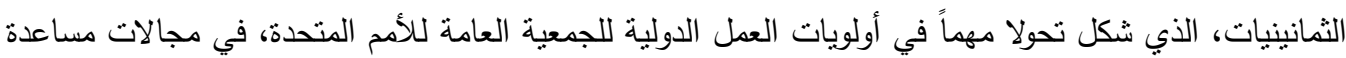

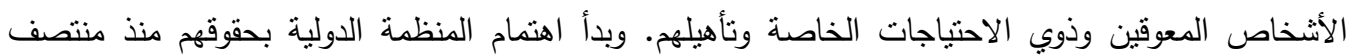

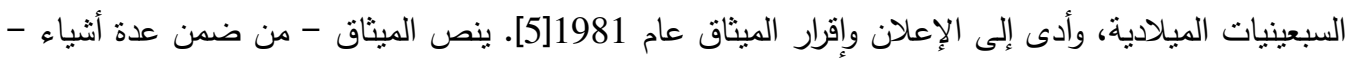

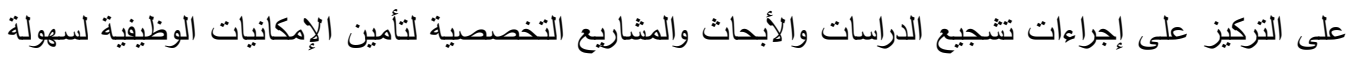

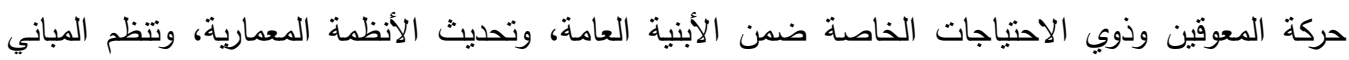

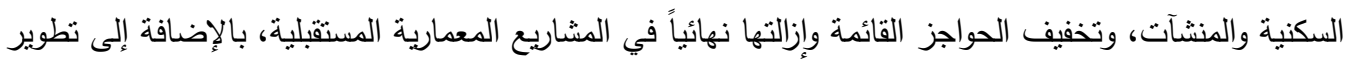

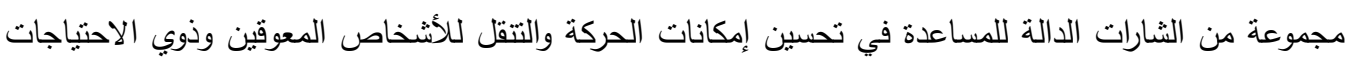
الخاصة [6]. ولتحديد المبادئ الأساسية المطلوبة للتصميم للمعوقين في البيئة الخارجية، وفق المفاهيم والاعتبارات التي تم

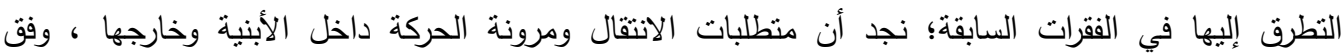

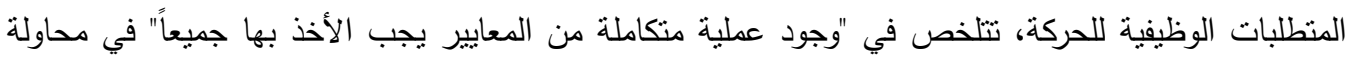

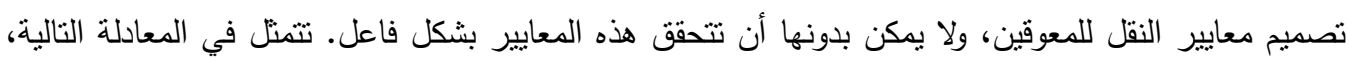
وهي: عملية الوصول - الدخول - واستعمال البيئة المبنية. لا يزال موضع الموقع الوظيفي لمعايير التصميم

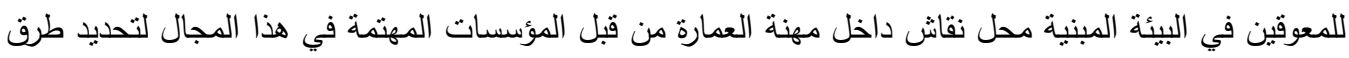

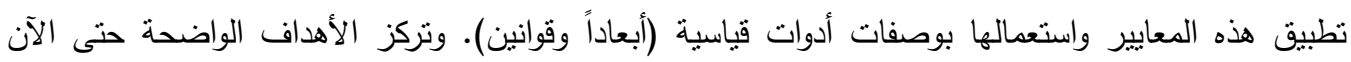

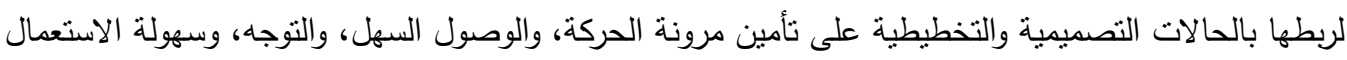
والعمل بشكل آمن وسليم، انظر الجدول رقم (1) [7].

\section{الجدول رقم (1): يوضح بعض معايير تحديد أهداف واستراتيجيات تسهيل نقل المعوقين [7]:}

\begin{tabular}{|c|c|}
\hline 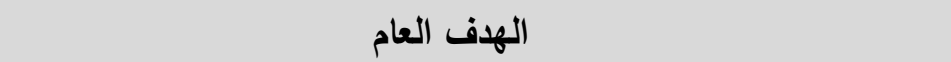 & المعايير \\
\hline تصميم البيئة المبنية بحيث تتوفر مرونة الحركة. & مرونة محاور الحركة \\
\hline بدون عوائقر. & وصول ســل \\
\hline استعمال البيئة المبنية من قبل الجميع. & سهولة الاستعمال \\
\hline توضيح وتمييز المسالك والطرقات وممرات المشاة أو الممرات العامة، ومحطات & سـهولة التوجه \\
\hline
\end{tabular}




\begin{tabular}{|c|c|}
\hline النقل. & \\
\hline تأمين حركة الأثخاص دون خوف أو خطر على الصحة العامة وتقليل الحوادث. & الأمـان والسلامة \\
\hline تصميم أماكن العمل بشكل يسمح باشتراك المعوقين والأصحاء. & 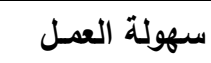 \\
\hline
\end{tabular}

تؤكد المراجـع البحثيـة المختلفـة والخاصـة بـالمعوقين وذوي الاحتياجـات الخاصـة على الاهتمـام الكبير الذي تحظى به الإعاقة الجسدية، حيث يؤكد كولد سميث (Goldsmith) أن معايير التصميم للحركة الثخصية تحدد بشكل كبير الطريقة التي يتحرك فيه الأشخاص من مكان لآخر ، فبينما يمشي الأشخاص العاديون على قدمين مـع

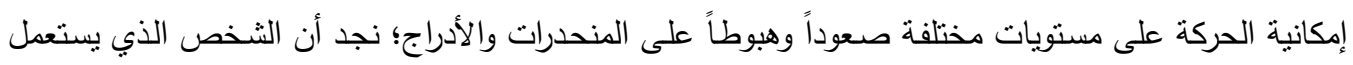
المقعد المتحرك مهما امتلك من الخبرة والقوة الجسدية يحتاج إلى مصعد للصعود إلى أعلى أو يتم حمله من قبل أثخاص آخرين، وهنا تكمن أهمية المنحدرات كإجابة عن مشكلة تصميمية تتعلق بالمعوقين بالإضافة إلى الوسائل التقنية الأخرى المساعدة [8].

ويعتمد قسم من الأشخاص المعوقين وذوي الاحتياجات الخاصة ضمن هذه الفئة على الأدوات المساعدة والتقنيات منل العكاز ، والمسند المتحرك، أو نركيب أطراف صناعية. إن المشكلات التي يواجهونها في حركتهم ضمن البيئة نرجع بصورة رئيسية إلى حاجتهم على استعمال الكرسي المتحرك، والتي لها علاقة بمشكلة التجول، أو العمل من خلال الكرسي المتحرك، فمعظم متطلبات هذه الفئة لها علاقة بأبعاد وطبيعة الكرسي المتحرك. ومعظم الأبعاد والمقاييس المنداولة مأخوذة من منطلبات العديد من البلدان الصناعية. وبشكل عام نجد أن المعماريين والمخططين كانوا دائمي الاهتمام بضرورة تأمين الاحتياجات الوظيفية لمستعملي الأبنية، ونم بشكل خاص استثمار الأبحاث المعرفية التي تمت في هذا المجال، خلال العقدين الأخيرين، وخاصة التحول المهم نحو الحاجة إلى تفهم الاحتباجات الوظيفية، بمحتواها العام، والتي تعكس كيفية تعامل الإنسان مع البيئة المبنية، حيث نوسعت الأبحاث التخصصية في العلوم الإنسانية لنشمل اختصاصات التصنية متعددة وشاملة [9].

إن اختلاف وتعدد مناهج التعامل مع هذه الاختصاصات في تحديد أولويات منطلبات الإنسان أظهر مناهج وطرق جديدة في العمل المعماري الحالي، حيث تم استثماره لصالح إيجاد بيئة مناسبة للأشخاص المعوقين في معظم بلدان العالم [10]. فقد تم تحديد معايير منطلبات الإنسان ومستعملي الأبنية والمرافق العامة، من قبل (المركز الدولي للأبحاث ودراسات الأبنية) على أنه"المستوى والثروط الضرورية للإنسان كي يعيش ويعمل براحة، وأمان، وفق المعايير الصحية، والمؤهلات الاقتصادية المطلوبة" [11]. يحتاج المعوقون جسدياً إلى العديد من الخدمات مثل: الخدمات الطبية، والخدمات التعليمية والمهنية، والخدمات الاجتماعية، والخدمات الترويحية والترفيهية، والخدمات الرياضية، والخدمات التكيفية والتي تتمل خدمات تكييف

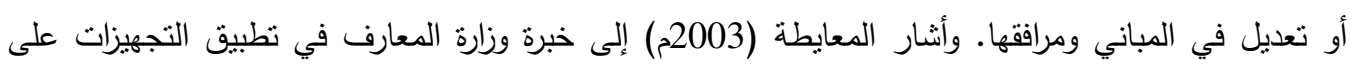
مبانيها، حيث وضعت الوزارة مجموعة من الثروط والضوابط الفنية لتصميم وإنشاء المباني المدرسية، مراعية بذلك دئك حاجات ذوي الاحتياجات الخاصة، والتي تتلخص بالأمور التالية [12]: 
1- أن تكون مداخل المدارس لمراحل التعليم جميعها بعرض خاص (5م) للسماح بدخول عربة الطوارئ بسهولة ويسر عند الحاجة إليها.

2- أن تكون الإدارة وخدماتها من وكلاء وسكرتارية ومرشد طلابي ومكاتب معلمين ودورات مياه في الدور الأرضي.

3- أن تكون معامل الفيزياء والكيمياء والأحياء والحاسب والعلوم للمرحلة الابتدائية وغرف التحضير في الدور الأرضي.

4- أن تكون قاعات الأنشطة والهوايات والدكتبة وغرفة مصادر التعلم، ومشغل التربية الفنية، وغرفة التربية البنية، والصالات متعددة الأغراض في الدور الأرضي. 5- تخصيص دورات مياه للطلاب المعوقين بمساحة (3.5م2) في الدور الأول.

6- - توفير مغاسل للطلبة المعوقين جسدياً بارتفاعات مناسبة.

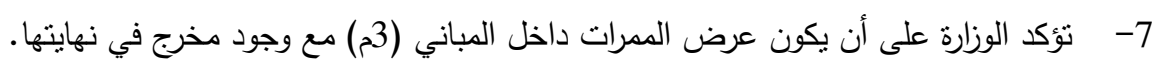

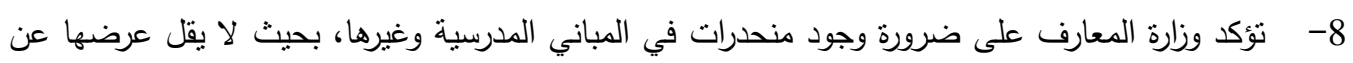

(1.5م) وأن لا يزيد طولها عن (9م). وبنسبة انحدار 9- تشترط وزارة المعارف توفير أبواب للغرف الصفية سهلة الفتح وخالية من الأقفال، ولها مقابض جانبية غير متحركة.

وبينما دول العالم تركز البحث لصالح إيجاد بيئة مناسبة للأشخاص المعوقين ولإيجاد وسائل عملية لحماية

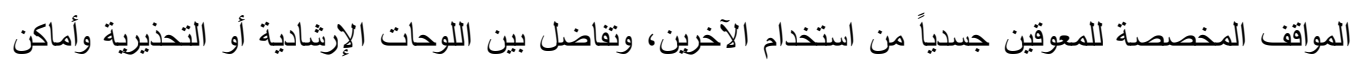

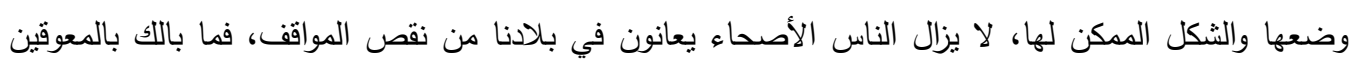

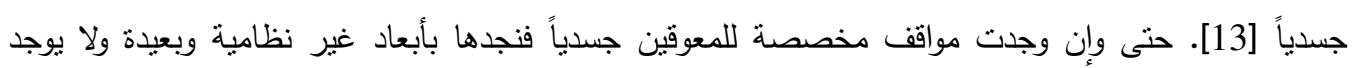

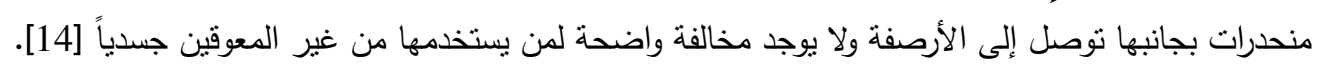

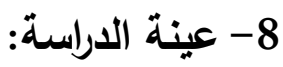

تشمل عينة البحث جميع مباني الكليات التي صمدت وشيدت وافتتحت خلال السنوات العشر الماضية. هذه العينة من المباني شملت الكليات التالية: 1. كلية العمارة والتخطيط (المبنى رقم 32):

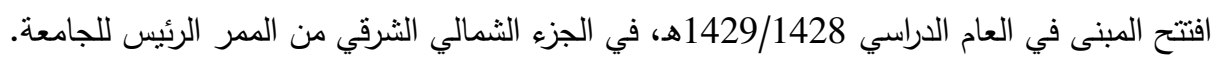

2. كلية علوم الحاسب والمطلومات (المبنى رقم 31):

افتتح المبنى في العام الدراسي 1430/1429هـ، في الجزء الثرقي من المعر الرئئيس للجامعة.

3. كلية العلوم الطبية التطبيقية (المبنى رقم 24):

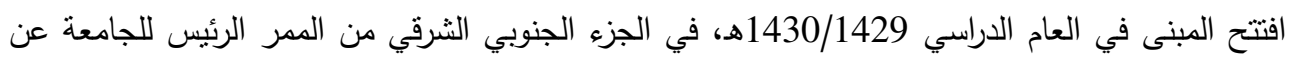
طريق ارتباطه بالممر الرئيس الفاصل بين كليتي الصيدلة وطب الأسنان. 
4. كلية اللغات والترجمة (المبنى رقم 9):

افتتح المبنى في العام الدراسي 1431/1430هـ، في الجزء الجنوبي الغربي من المر الرئيس للجامعة.

\section{9- الإعاقة الجسدية في عينة الدراسة:}

هنالك العشرات من ذوي الاحتياجات الخاصة بالجامعة بشكل عام وفي عينة الدراسة بشكل خاص، حيث يوضح الجدول رقم (2) أعداد المعوقين جسدياً من أعضاء هيئة التدريس والموظفين والطلاب حسب كل كلية. وغالبية الدعوقين جسدياً من الموظفين يليهم أعضاء هيئة التنريس ومن ثم الموظفون. وهذا ما يعطي الدئ الدراسية أهمية كبرى لكونها ستسهم في توفير بيئة تيسر وتسهل حركة المعوق وتهيئ له الأوضاع والأبعاد والفراغات المناسبة في الكليات التي يرتادها للعمل أو الدراسة.

الجدول رقم (2): يوضح أعداد تصاريح المعوقين المصدرة للكليات من تاريخ 1426/12/28هـ وحتى 1430/10/17

\begin{tabular}{|c|c|c|c|c|c|c|}
\hline \multirow[t]{2}{*}{ المجموع } & \multicolumn{3}{|c|}{ أعداد المعوقين طبقاً لإدارة } & \multirow{2}{*}{ الموقع بالنسبة للممر } & \multirow{2}{*}{ تاريخ الافتتاح } & \multirow[t]{2}{*}{ الكلية } \\
\hline & طلاب & موظفون & مدرسون & & & \\
\hline 15 & 2 & 9 & 4 & الجزء الثمالي & العام الدراسي & العمـارة والتخطيط \\
\hline 12 & 5 & 5 & 2 & الجزء الثرقي & العام الدراسي & علـوم الحاسب \\
\hline 1 & - & 1 & - & الجزء الجنوبي & العام الدراسي & التولوم الطبية \\
\hline 35 & 8 & 16 & 11 & الجزء الجنوبي الغربي & العام الدراسي & اللغات والترجمـة \\
\hline 63 & 15 & 30 & 17 & & المجموع & \\
\hline
\end{tabular}

\section{-10 - نتائج الاراسة الميدانية:}

لقد اتضح من خلال الزيارات الميدانية أنه لا يوجد من مباني الكليات الأربع الجديدة التي ضمتها عينة البحث مبنى واحد يمكن أن يستخدمه المعوق، والسبب يتمثل في مشكلتين أساسيتين هما: 
1. عدم وجود لوحات إرشادية ولافتات دالة خارجية وداخلية خاصة بالمعوقين - وغيرهم - تبين اتجاهات وأماكن

وجود الخدمات الخاصة بهم منل: الدداخل، والمخارج، والمصاعد، ودورات المياه، ..إلخ.

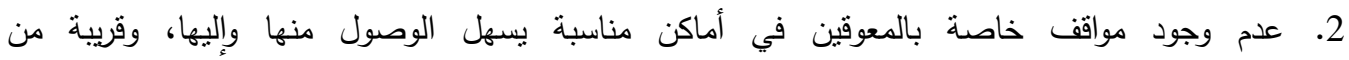

المداخل/المخارج الرئيسة والفرعية.

والاشتراطات الأخرى مثل : المنحدرات، والأرصفة، والأبواب، والممرات، والمصاعد، ودورات المياه متوفرة ولكن

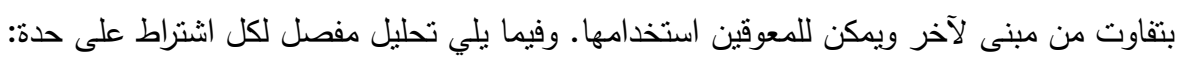

10 -10 - 10 اللوحات الإرشادية الخارجية:

هناك عدة لوح دالة ثانوية من المفترض توافرها أمام جميع مباني الكليات الأربع لكي يستدل ذوو الاحتياجات

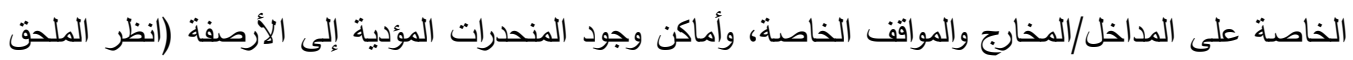

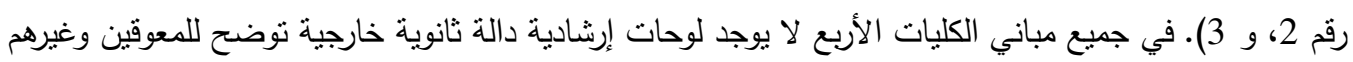

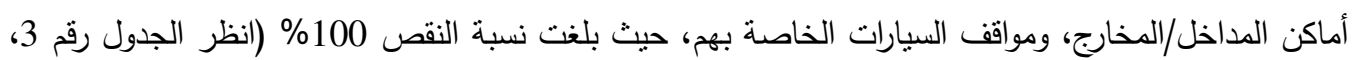

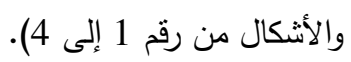

الجدول رقم (3): يوضح اللوحات الإرشادية والللافتات الخارجية المفترضة لمداخل ولمخارج ولمواقف

كل كلية جديدة:

\begin{tabular}{|c|c|c|c|c|c|}
\hline \multirow{2}{*}{ ملاحظات } & \multicolumn{2}{|c|}{ اللوحات الإرشادية } & \multicolumn{2}{|c|}{ اللمداخل/الإرشادية المخارج } & \multirow{2}{*}{ اسم الكلية } \\
\hline & 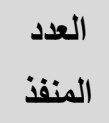 & 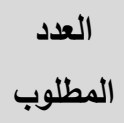 & المدفد & المطلوب المبد & \\
\hline المواقف المخصصة لطلاب الكلية رقم (12) & لا يوجد & 12 & لا يوجد & 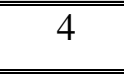 & العمارة والتخطيط \\
\hline (51) الطلاب بستخدمون مواقف الصالات الرياضية رقم & لا يوجد & 8 & لا يوجد & 3 & علوم الحساسب \\
\hline الطلاب يستخدمون مواقف سكن الطلاب رقم & لا يوجد & 8 & ل الا يوجد & 3 & 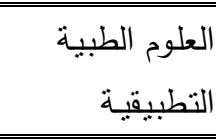 \\
\hline \multirow[t]{2}{*}{ الطلاب بستخدمون مواقف كلية العلوم رقم (19) } & ل الا يوجد & $\overline{77}$ & لا يوجد & 3 & اللغات والثرجمة \\
\hline & لا يوجد & 35 & لا يوجد & 13 & المجموع \\
\hline
\end{tabular}




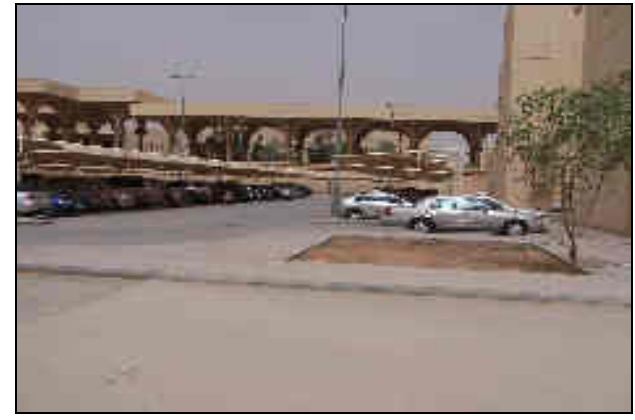

الثكل رقم (2): يوضح خلو مواقف كلية علوم الحاسب والمعلومات من أي لوح إرثنادية للمعوقين أو غيرهم.

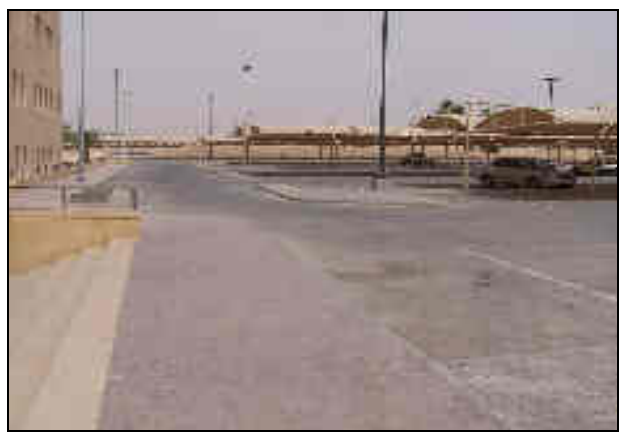

الشكل رقم (4): يوضح خلو مواقف كلية اللغات والترجمة من أي لوح إرشادية للمعوقين أو غيرهم.

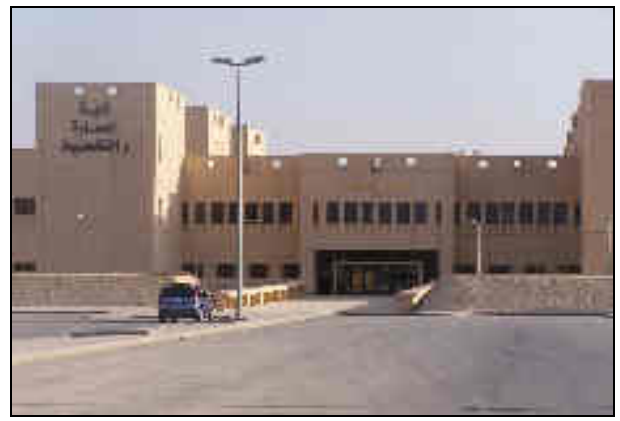

الثكل رقم (1): يوضح خلو مواقف كلية العمارة والتخطيط من أي لوح إرشادية للمعوقين أو غيرهم.

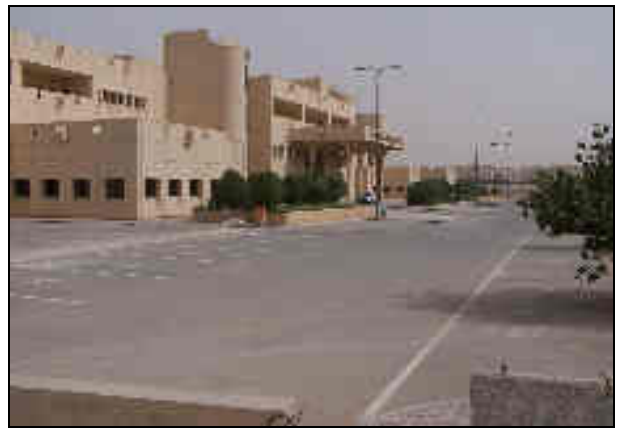

الثكل رقم (3): يوضح خلو مواقف كلية العلوم الطبية التطبيقية من أي لوح إرشادية للمعوقين أو غيرهم.

\section{10-2- مواقف السيارات:}

على الرغم من أن الكليات الأربع فيها معاقون حسبما هو مذكور في الجدول رقم (2) إلا أنها جميعاً غير مزودة بمواقف نظامية للمعوقين بالدور الأرضي، أو غيره من الأدوار ـ ونم إصدار تصاريح دخول لهذه الفئة بحيث يستطيع حاملها الدخول إلى مواقف الخدمات. كما أن دخولهم إلى تلك المواقف لا يضمن لهم مواقف خاصنة وقريبة من المداخل، بل هم يتتافسون مع حملة التصاريح الدخول "الذهبية" و "الطوارئ" على مواقف معدودة ليست

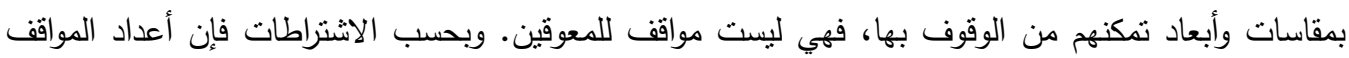
المفترض توافرها للمعوقين في الكليات الأربع هو 283 موقفاً، إلا أنه لا يوجد موقف واحد بأبعاد نظامية ومخصص للمعوقين (انظر الجدول رقم 4). 
الجدول رقم (4): يوضح أعداد المواقف المفترض توفرها لذوي الاحتياجات الخاصة في كل

كلية جليدة:

\begin{tabular}{|c|c|c|c|c|c|}
\hline عداقد مواقف & المعدوقين & المواقف & المستخدمون & رقم & الكلية \\
\hline لا يوجد & 9 & 173 & مدرسون/موظفون & بدون & \multirow[t]{2}{*}{ العمارة والتخطيط } \\
\hline لا لا يوجد & 70 & 1392 & طلاب & 12 & \\
\hline لا يوجد & 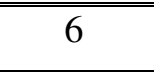 & 1113 & مدرسون/موظفون & بدون & \multirow{2}{*}{ علوم الحاسب } \\
\hline لا يوجد & 79 & 1577 & طلاب & 51 & \\
\hline لا يوجد & 7 & 123 & مدرسون/موظفون & بدون & \multirow{2}{*}{ التطلوم الطبية } \\
\hline لا يوجد & 38 & 757 & طلاب & 52 & \\
\hline لا يوجد & 5 & 100 & مدرسون/موظفون & بدون & \multirow[t]{2}{*}{ للغات والتزرجمـة } \\
\hline لا يوجد & 69 & 1372 & طلاب & 19 & \\
\hline لا يوجد & 283 & 5607 & \multicolumn{3}{|c|}{ المجموع } \\
\hline
\end{tabular}

3-10-30 المندرات المؤدية إلى الأرصفة الخارجية:

بالرغم من أن هناك نقصاً في أعداد المنحدرات بلغت نسبته قرابة 41,6\% كما يتضح من الجدول رقم (5) إلا

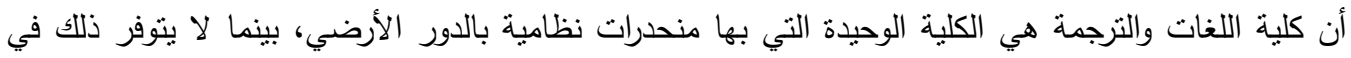
بقية الكليات الثلاث (أنظر الأثكال من رقم 5 إلى 8).

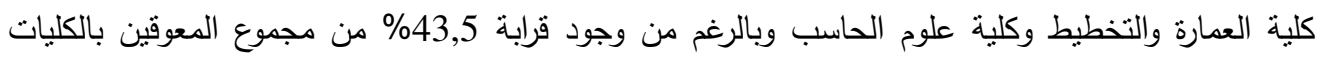

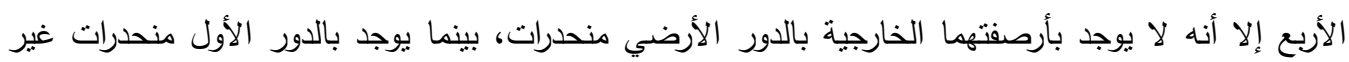
مكثملة لا يمكن لكرسي المعوق السير عليها (انظر الثكلين رقم 9 و 10 ). 
FACT OF THE APPLICATION OF REQUIREMENTS ...

\begin{tabular}{|c|c|c|c|c|c|c|}
\hline \multirow{2}{*}{ مواد الإنهاء } & \multicolumn{2}{|c|}{ أبعاد المنحدر } & \multirow[b]{2}{*}{ العند العنذ } & \multirow[b]{2}{*}{ المطدد } & \multirow[b]{2}{*}{ مكان الرصيف } & \multirow[b]{2}{*}{ اسم المشروع } \\
\hline & العرض & الطول & & & & \\
\hline- & - & - & لا يوجد & 2 & الشرق/الدور الأرضي & \multirow{4}{*}{ العمـارة } \\
\hline- & \multicolumn{4}{|c|}{ 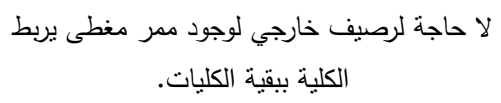 } & الغرب/الدور الأول & \\
\hline بـبردورة أســنتي خشـن منتهي & 0.90 & 6 & 1 & 2 & الثمال/الدور الأول & \\
\hline بـبردورة أسـمنتي خثـن منتهي & 2 & 7.40 & 1 & 2 & الشرق/الدور الأول & \\
\hline بـبردورة أسـمنتي خشـن منتهي & & & 6 & 6 & الجنوب/الدور الأرضي & \multirow{4}{*}{ علوم الحاسب } \\
\hline- & - & - & لا يوجد & 2 & الشرق/الدور الأرضي & \\
\hline- & \multicolumn{4}{|c|}{ لا حاجة لرصيف خارجي لوجود ممر مغطى يربط } & الغرب/الدور الأول & \\
\hline بـلاط أسـمنتي خثـن منتهـي & 2 & 7.40 & 1 & 2 & الشرق/الدور الأول & \\
\hline بـبردورة أســنتي خشـن منتهي & 1.60 & 2 & $\overline{11}$ & 3 & الشرق/الدور الأرضي & \multirow{3}{*}{ العلوم الطبية } \\
\hline- & - & - & لا يوجد & 1 & الغرب/الدور الأرضي & \\
\hline- & \multicolumn{4}{|c|}{ لا حاجة لرصيف خارجي لوجود ممر مغطى يربط } & الغرب/الدور الأول & \\
\hline ترابيع حجر الرياض & 1.15 & 6.80 & 2 & 2 & الثمال/الدور الأرضي & \multirow{3}{*}{ والترجمة } \\
\hline بلاط أسمنتي خشن منتهي & 0.90 & 6 & 2 & 2 & الغرب/الدور الأرضي & \\
\hline- & \multicolumn{4}{|c|}{ 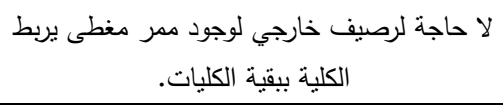 } & الجنوب/الدور الأول & \\
\hline & & & 14 & 24 & ل & \\
\hline
\end{tabular}

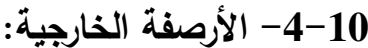

معظم الأرصفة الخارجية بالدور الأرضي ذات عروض نظامية نمكن كرسي المعوق من الحركة عليها بيسر 


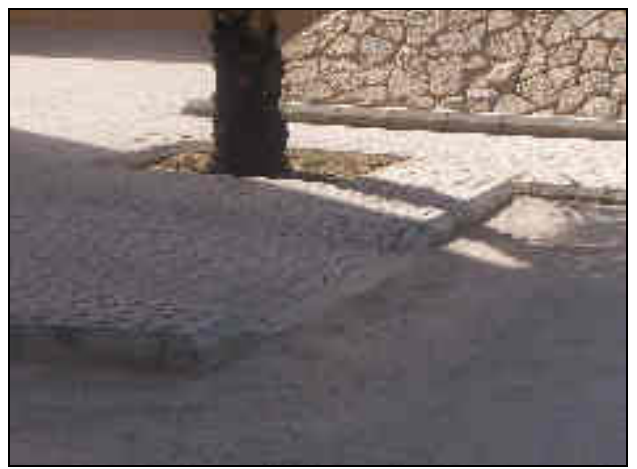

الثكل رقم (6): يوضح أحد المنحدرات النظامبة بكلية اللغات والترجمة.

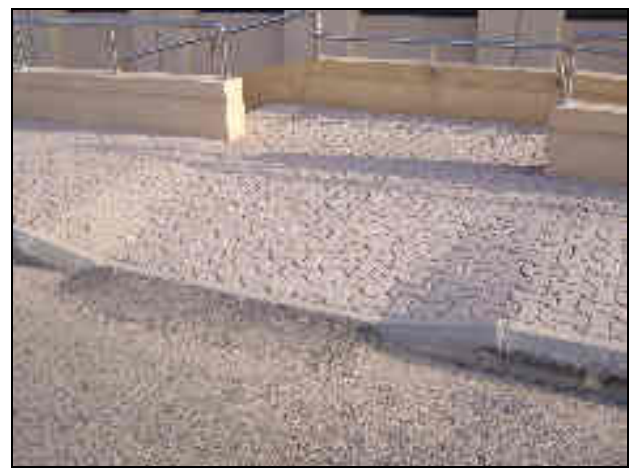

الشكل رقم (8): يوضح أحد المنحدرات النظامية بكلية علوم الحاسب والمعلومات.

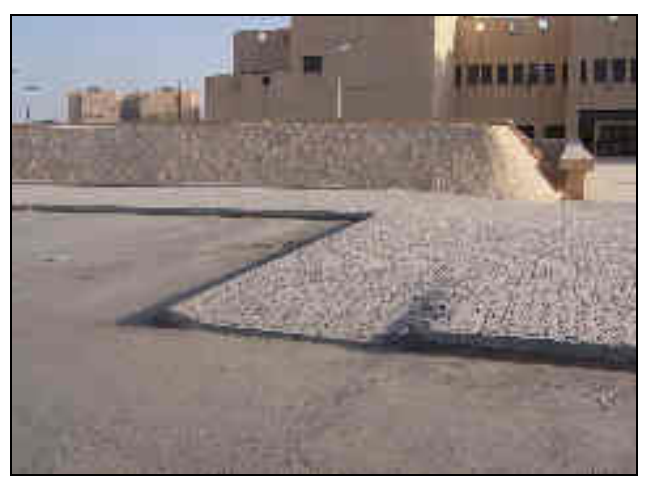

$$
\text { الشكل رقم (10): يوضح أحد المنحدرات الغير }
$$

نظامية المؤدية إلى الرصيف بالدور

الأول لكلية العمارة والتخطيط.

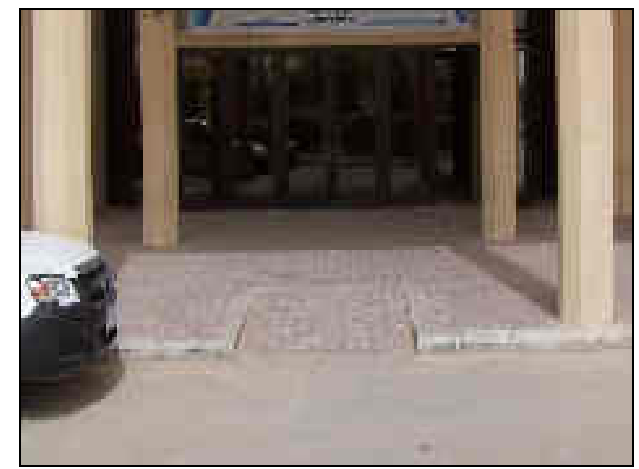

الثكل رقم (5): يوضح أحد المنحدرات النظامية بكلية

العلوم الطبية التطبيقية.

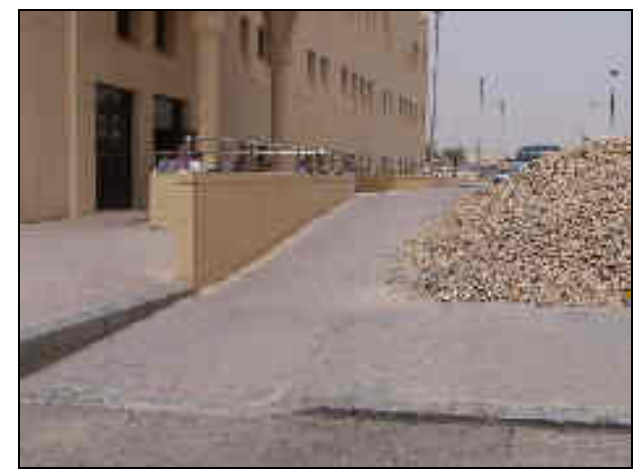

الثكل رقم (7): يوضح أحد المنحدرات النظامية بكلية

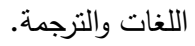

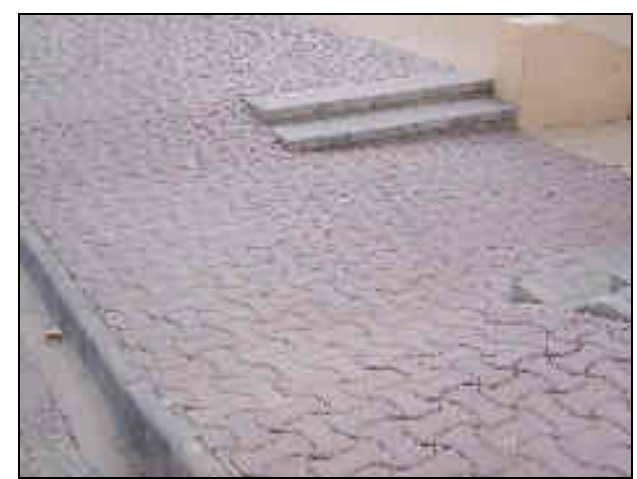

الثكل رقم (9): يوضح أحد المنحدرات الغير نظامية بالدور الأول بوض لكلية علوم الحاسب والمعلومات. 
10-5- المندرات المؤدية إلى المداخل والمخارج:

الغالبية العظمى من المداخل الرئيسة للمباني قيد البحث لا تحتاج إلى منحدرات لكونها في منسوب الأرصفة.

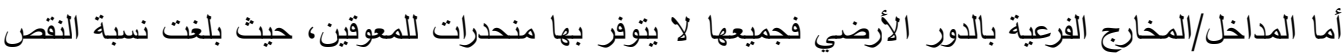
بها قرابة 27,3\% (انظر الجدول رقم 7، والأشكال من رقم 11 إلى 16).

\section{الجدول رقم (7): يوضح مندرات مؤدية إلى المداخل/المخارج في كل كلية جديدة:}

\begin{tabular}{|c|c|c|c|c|c|c|c|}
\hline \multirow{2}{*}{ ملاحظات } & \multirow{2}{*}{ 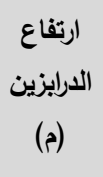 } & \multicolumn{2}{|c|}{ أبعاد المنحدر } & \multirow{2}{*}{ العنفذ } & \multirow{2}{*}{ المطلوب } & \multirow{2}{*}{ مكان المدخل/المخرج } & \multirow{2}{*}{ اسم المشروع } \\
\hline & & $\begin{array}{l}\text { العرض } \\
\text { (م) }\end{array}$ & $\begin{array}{l}\text { الطول } \\
\text { (م) }\end{array}$ & & & & \\
\hline بوجد فرق منسوب & لا يوجد & لا يوجد & ل لا يوجد & لا يوجد & 1 & الثرق/الدور الأرضي & \multirow{5}{*}{ العمـارة والتخطيط } \\
\hline منحدر خاص بالورش & 0.90 & 1.90 & 13.40 & 2 & 2 & الجنوب/الدور الأرضي & \\
\hline لا يوجد فرق منسوب & - & & - & - & - & الغرب/الدور الأول & \\
\hline لا يوجد فرق منسوب & - & & - & - & - & الثمال/الدور الأول & \\
\hline لا يوجد فرق في & - & & - & - & - & الثرق/الدور الأول & \\
\hline لا يوجد فرق منسوب & - & & - & - & - & الثرق/الدور الأول & \multirow{3}{*}{ علوم الحاسب } \\
\hline بوجد فرق منسوب & لا يوجد & لا يوجد & ل لا يوجد & لا يوجد & 1 & الثرق/الدور الأرضي & \\
\hline منحدر خاص بالورش & 0.90 & 1.90 & 13.40 & 2 & 2 & الثمال/الدور الأرضي & \\
\hline لا يوجد فرق منسوب & - & - & - & - & - & الثرق/الدور الأرضي & \multirow{3}{*}{ التطبيقيـة الطبية } \\
\hline بوجد فرق منسوب & لا يوجد & لا يوجد & ل لا يوجد & لا يوجد & 1 & الغرب/الدور الأرضي & \\
\hline لا يوجد فرق منسوب & - & - & - & - & - & الغرب/الدور الأول & \\
\hline فرق المنسوب 18سم & لا يوجد & 1.80 & 1.80 & 2 & 2 & الثمال/الدور الأرضي & \multirow{3}{*}{ اللغات واللترجمـة } \\
\hline فرق المنسوب 18سم & لا يوجد & 1.80 & 1.80 & 2 & 2 & الغرب/الدور الأرضي & \\
\hline لا يوجد فرق منسوب & - & - & - & - & - & الجنوب/الدور الأول & \\
\hline & & & & 8 & 11 & & المجموع \\
\hline
\end{tabular}



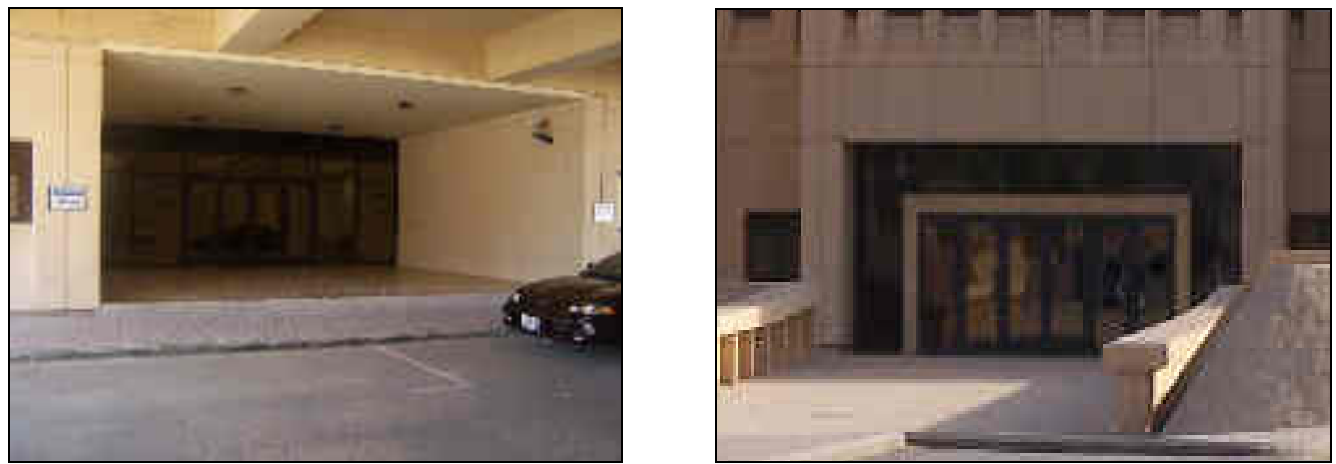

الثكل رقم (11): يوضح عدم وجود فرق في المنسوب الثكل رقم (12): يوضح وجود فرق في المنسوب أمام أمام مدخل كلية العمارة والتخطيط الثمالي بالدور الأول. مدخل كلية العمارة والتخطيط الثرقي بالدور الأرضي.
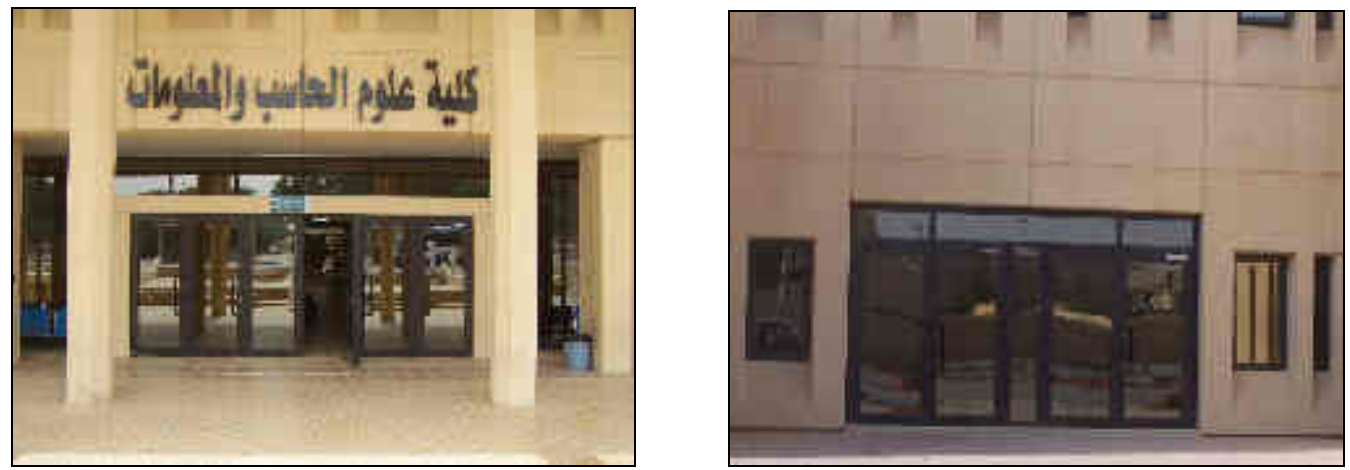

$$
\text { الثكل رقم (14): يوضح عدم وجود فرق في المنسوب النماب }
$$

الثكل رقم (13): يوضح عدم وجود فرق في المنسوب أمام مدخل كلية علوم الحاسب والمعلومات الثرقي. أمام مدخل كلية علوم الحاسب والمعلومات الجنوبي.

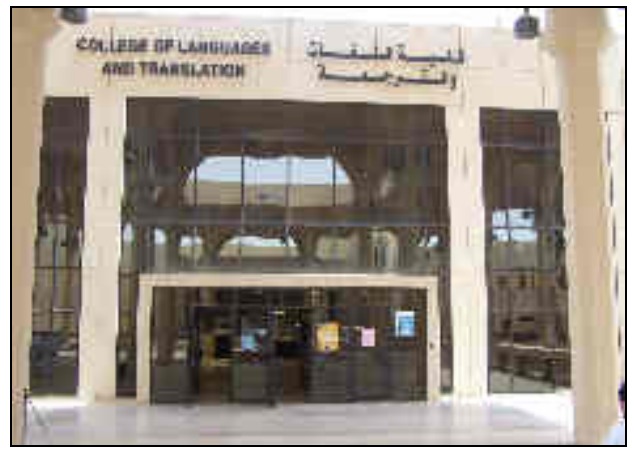

الثكل رقم (16): يوضح عدم وجود فرق في المنسوب أمام مدخل كلية اللغات والترجمة الجنوبي.

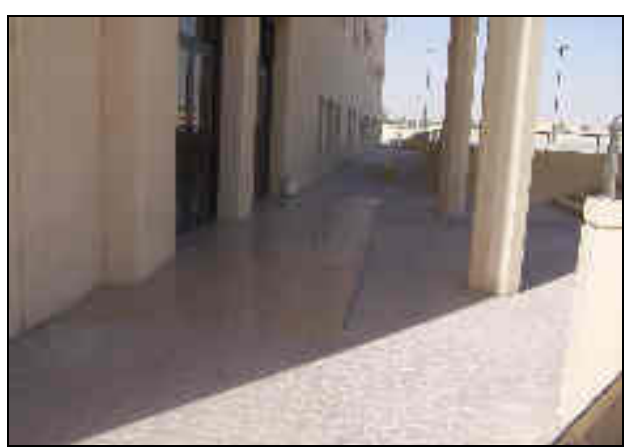

الثكل رقم (15): يوضح وجود منحدر أمام مدخل كلية

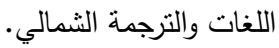


-6-10- الأبواب (المد/خل/المخارج):

جميع أبواب المداخل/الدخارج الرئيسة بمباني الكليات الأربع قيد البحث ذات عروض نظامية (لا تقل عن

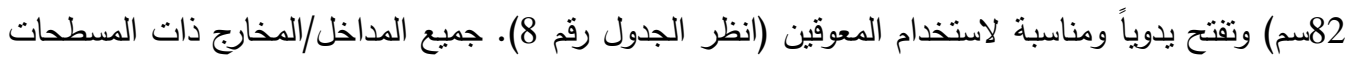

الزجاجية بالكامل لم نزود بعلامات واضحة في مستوى النظر لتجنب الاصطدام بها. الجدول رقم (8): يوضح الأبواب (المداخل/المخارج):

\begin{tabular}{|c|c|c|c|c|c|}
\hline ملاحظات & مواد الصنع & العرض & العدد & موقع الباب & اسم المشروع \\
\hline تفتح يدوياً للخارج & زجاج بالألمنيوم & 0.90 & 6 & |الغرب/الدور الأول & \multirow{4}{*}{ العمارة والتخطيط } \\
\hline تفتح يدوياً للخارج & زجاج بالألمنيوم & 0.90 & 6 & الشمال/الدور الأول & \\
\hline تقتح يدوياً للخارج & زجاج بالألمنيوم & 0.90 & 6 & |الثرق/الدور الأول & \\
\hline تقتح يدوياً للخارج & زجاج بالألمنيوم & 0.90 & 6 & الثرق/الدور الأرضي & \\
\hline تفتح يدوياً للخارج & | زجاج بالألمنيوم & 0.90 & 6 & |الغرب/الدور الأول & \multirow{3}{*}{ علوم الحاسب } \\
\hline تفتح يدوياً للخارج & |زجاج بالألمنيوم & 0.90 & 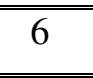 & الشرق/الدور الأول & \\
\hline تفتح يدوياً للخارج & |زجاج بالألمنيوم & 0.90 & $\overline{66}$ & الثشرق/الدور الأرضي & \\
\hline تقتح يدوياً للخارج & زجاج بالألمنيوم & 0.90 & 6 & الثرق/الدور الأرضي & \multirow{3}{*}{ التطلوم الطبية } \\
\hline تفتح يدوياً للخارج & |زجاج بالألمنيوم & 0.90 & 6 & الغرب/الدور الأول & \\
\hline تفتح يدوياً للخارج & |زجاج بالألمنيوم & 0.87 & 4 & الغرب/الدور الأرضي & \\
\hline تفتح يدوياً للخارج & |زجاج بالألمنيوم & 0.87 & 4 & الثمال/الدور الأرضي & \multirow{3}{*}{ اللغات والتزرجـــة } \\
\hline تفتح بدوياً للخارج & |ز زجاج بالألمنيوم & 0.87 & 4 & الغرب/الدور الأرضي & \\
\hline تقتح يدوياً للخارج & |ز زجاج بالألمنيوم & 0.87 & 4 & الجنوب/الدور الأول & \\
\hline
\end{tabular}

10-7-10 اللوحات الإرشادية الداخلية:

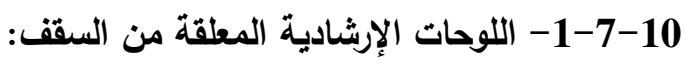

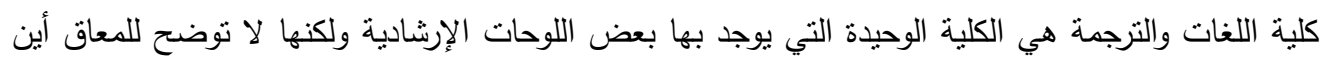

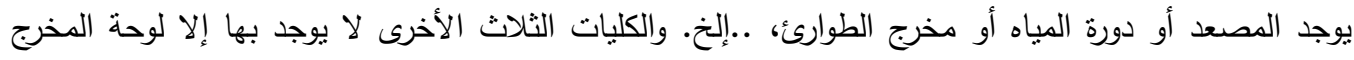

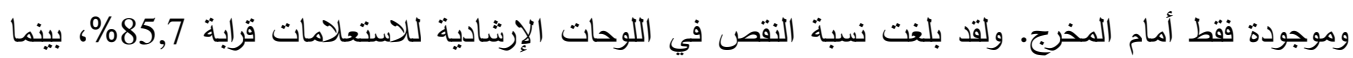
نسبة النقص في اللوحات الإرشادية للخارج الطوارئ قرابة 53\%. فيما ينعلق باللوحات الإرشادية للمصاعد ودورات المياه المعلقة من السقف فلقد بلغت نسبة النقص 100\% (انظر الجدولين رقم 9 و 10، والأثكال من رقم 
الجدول رقم (9): يوضح اللوحات الإرشادية والللافتات الداخلية المفترضة للاستعلامات ومخارج

الطوارئ لكل كلية جديدة:

\begin{tabular}{|c|c|c|c|c|c|}
\hline \multirow{2}{*}{ 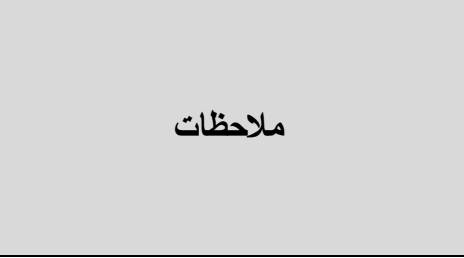 } & \multicolumn{2}{|c|}{ للمخارج الطوارئ الإشـادية } & \multicolumn{2}{|c|}{ للاستعلامات الإرشادية } & \multirow{2}{*}{ 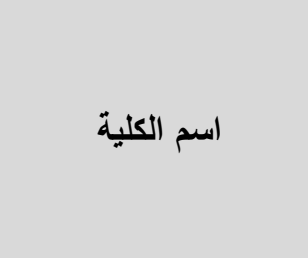 } \\
\hline & المنفذ & المطلوب المد & المنفذ & المطلوب & \\
\hline معلقة من السقف بجانب المخارج فقط & 27 & 60 & 1 & 4 & العمارة والتخطيط \\
\hline معلقة من السقف بجانب المخارج فقط & 24 & 48 & 1 & 4 & علوم الحاسب والمعلومات \\
\hline معلقة من السقف بجانب المخارج فقط & 30 & 60 & ل ل ايوجد & 3 & العلوم الطبية التطبيقية \\
\hline \multirow[t]{2}{*}{ معلقة من السقف بجانب المخارج فقط } & 12 & 30 & ل ل ال يوجد & 3 & اللغات والترجمـة \\
\hline & 93 & 198 & 2 & 14 & 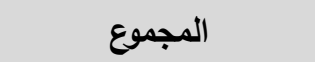 \\
\hline
\end{tabular}

الجدول رقم (10): يوضح اللوحات الإرشادية واللافتات الداخلية المفترضة للمصاعد ودورات المياه

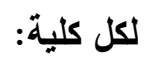

\begin{tabular}{|c|c|c|c|c|c|}
\hline \multirow{2}{*}{ ملاحظات } & \multicolumn{2}{|c|}{ لوحات إرشادية دورات المياه } & \multicolumn{2}{|c|}{ لوحات إرشادية للمصاعد معلقة } & \multirow{2}{*}{ اسم الكلية } \\
\hline & العدد المنفذ & العلوب العلوب & العدفد & العدد المطلوب & \\
\hline المعوقين وضعت بعيدة جداً عن المداخل. أربع دورات مياه & لا يوجد & 48 & لا يوجد & 24 & العمارة والتخطيط \\
\hline المعوقين وضعت بعيدة جداً عن المداخل. أربع دورات مياه & ل ل لا يوجد & 60 & ل ل ل ايوجد & 30 & والمعلوم الحاسب \\
\hline 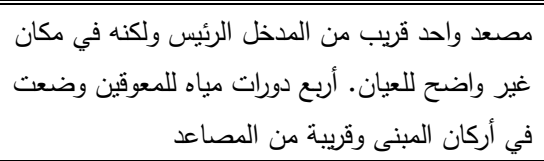 & لا يوجد & 60 & ل ل ل ل يوجد & 24 & العلوم الطبية التطبيقية \\
\hline \multirow[t]{2}{*}{ مصعد واحد قريب من المدخل الرئيس. } & لا يوجد & 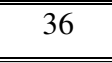 & ل الا يوجد & 12 & اللغات والترجمة \\
\hline & لا يوجد & 204 & لا يوجد & 90 & المجموع \\
\hline
\end{tabular}




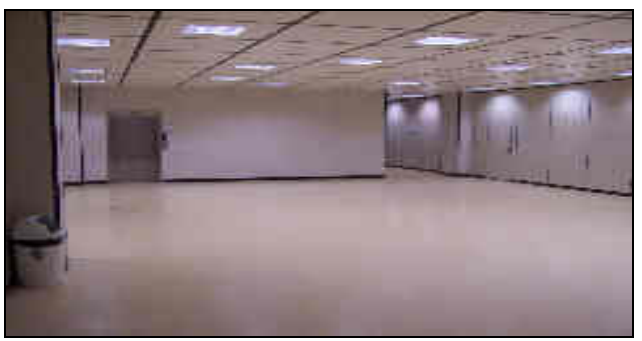

الثكل رقم (18):يوضح إحدى صالات بكلية العمارة والتخطيط، حيث لا يوجد بسققها أي لوح إرشادية.

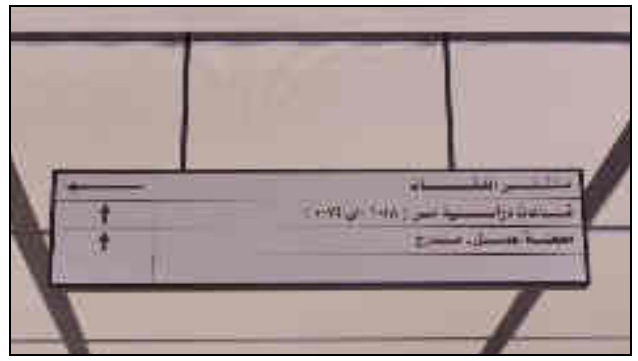

الثكل رقم (20): يوضح نوع آخر من اللوح الإرشادية المعلقة من السقف بكلية اللغات والترجمة.

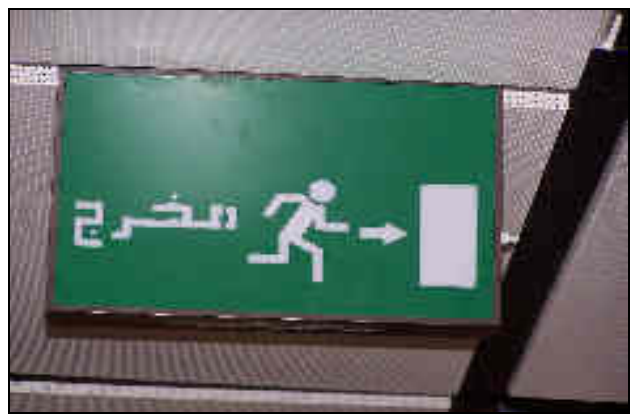

الثكل رقم (22):بوضح لوحة مخرج الطوارئ

المعلقة من السقف بطريقة إخراج وتعليق مختلفة.

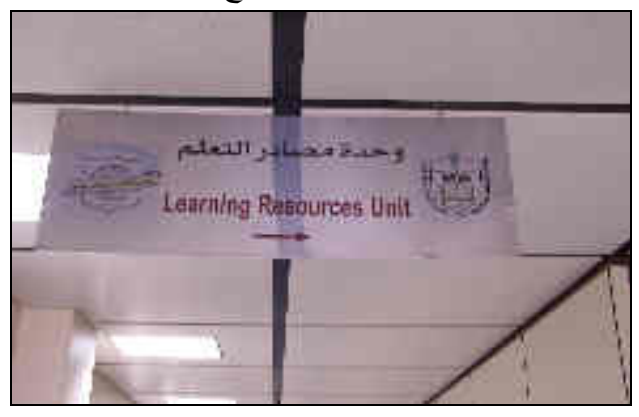

الثكل رقم (24): يوضح لوحة معلقة من السقق وضعت بجهذ فردي من وحدة التعليم بكلية

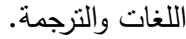

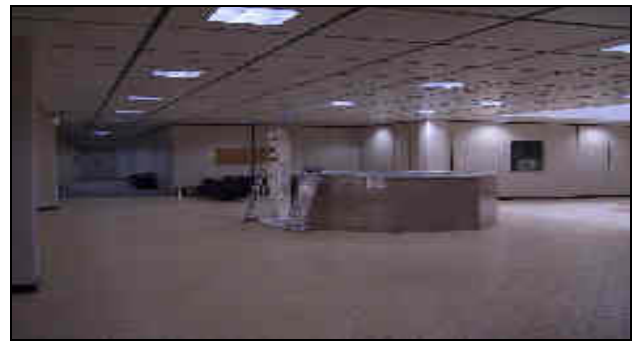

الثكل رقم (17): يوضح أحد مدخل كلية علوم الحاسب والمعلومات، حيث لا يوجد بسقفها أي لوح إرشادية.

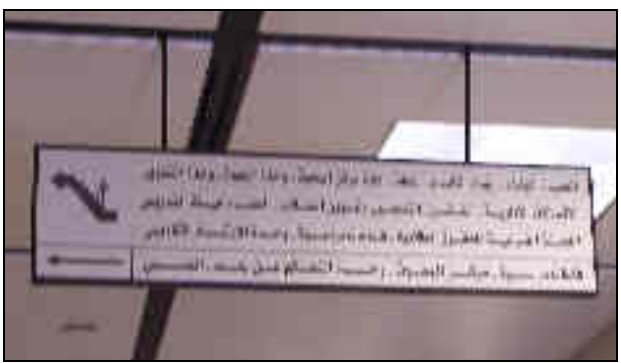

النكل رقم (19): يوضـح نوع من اللوح الإرشادية

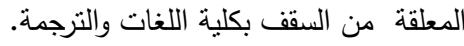

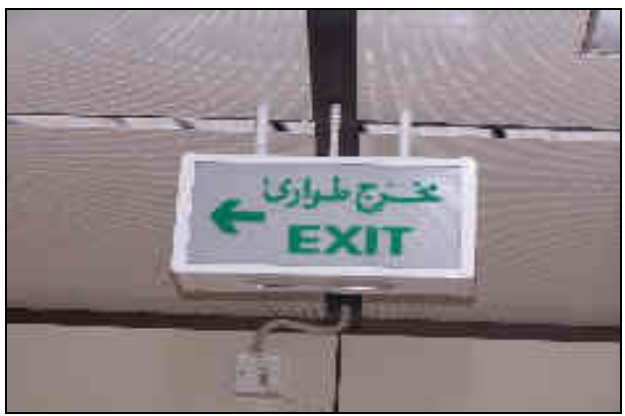

الثكل رقم (21): يوضح النوع الوحيد من اللوح المعلق من السقف والموجود في الكليات الأربع.

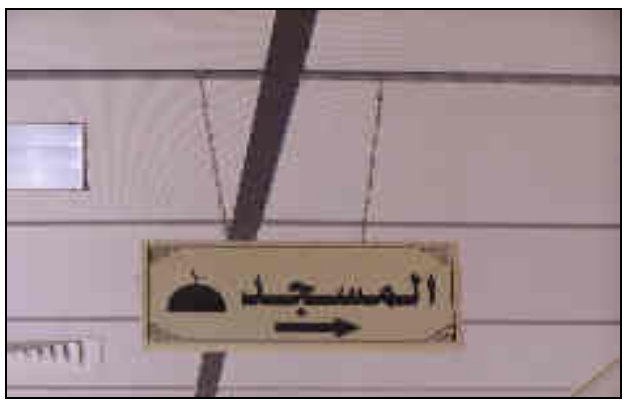

الثكل رقم (23): يوضح لوحة معلقة من السقق بجهد فردي من جماعة المسجد بكلية العلوم

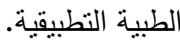




\section{2-7-10- اللوحات الإرشادية الجدارية:}

بالرغم من أن هذا النوع من اللوح موجود أكثر من غيره إلا أنه لا يشمل المعوقين، فمثلاً لا يوجد لوحة توضح

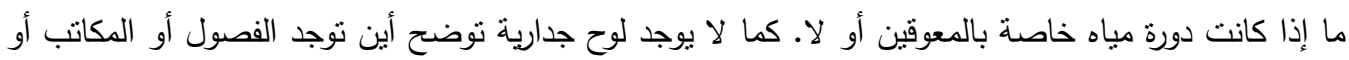

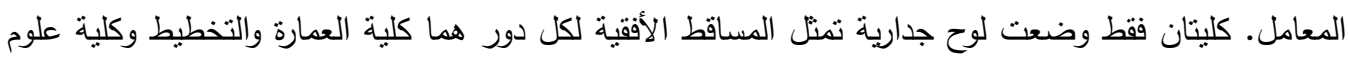

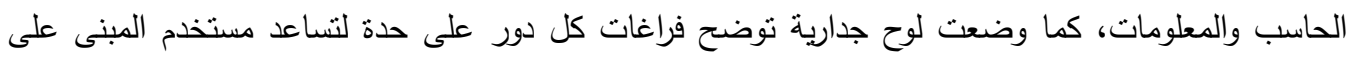

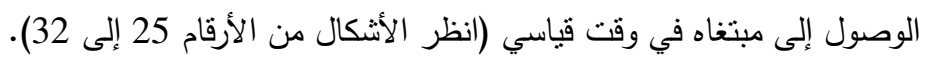

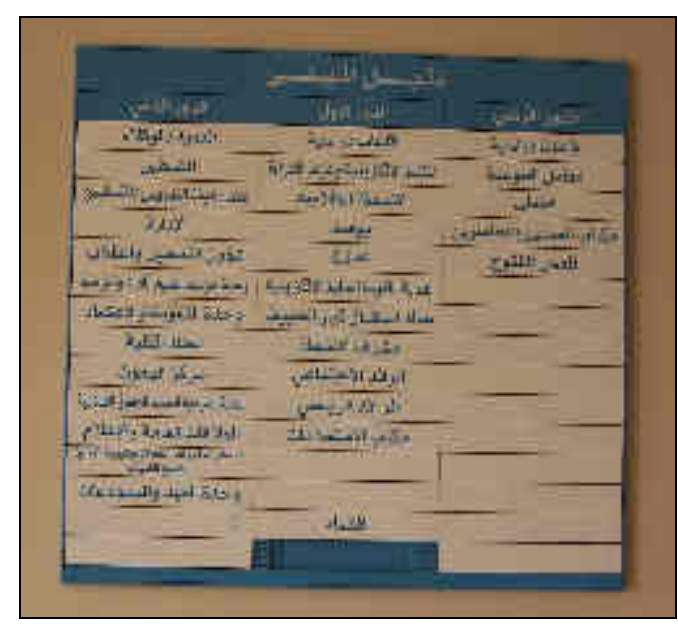

الثكل رقم (26): يوضح لوحة استعلامات جدارية بكلية علوم الحاسب والمعلومات.

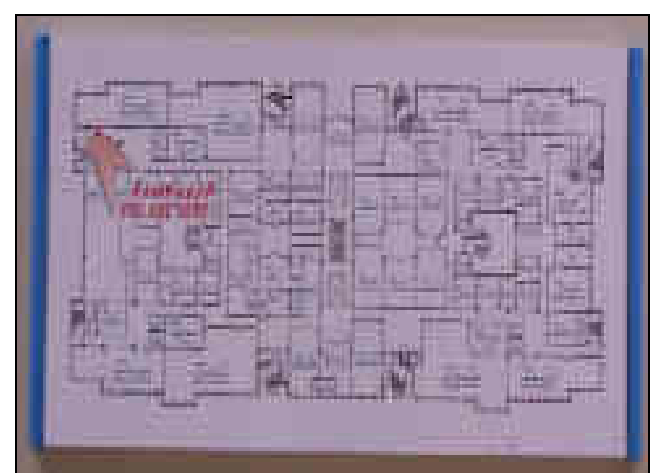

الثكل رقم (28): بوضح أحد لوح الاستعلامات في كلية العمارة والتخطيط.

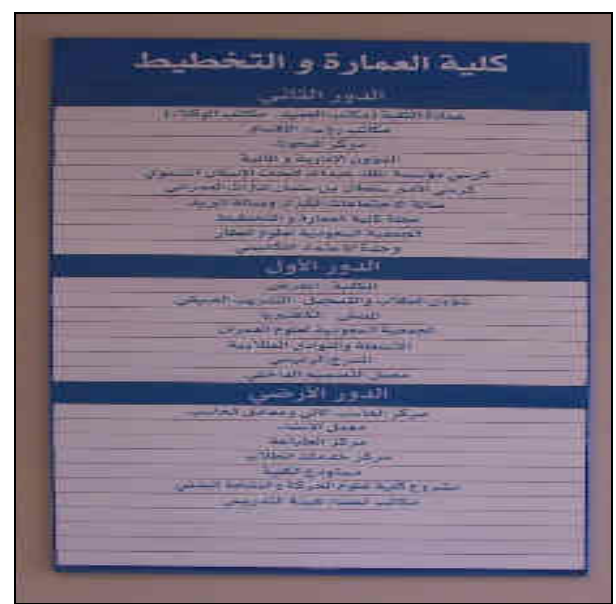

الثكل رقم (25): يوضح لوحة استعلامات جدارية بكلية العمارة والتخطيط.

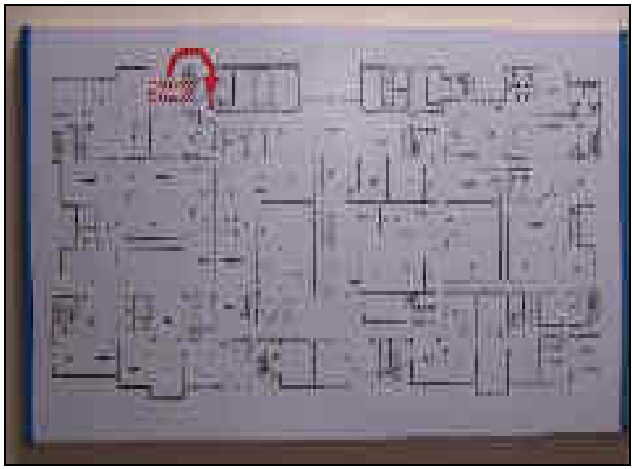

الثكل رقم (27): يوضح نوع آخر من لوح

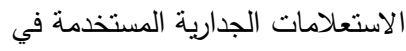
كلية علوم الحاسب والمعلومات. 

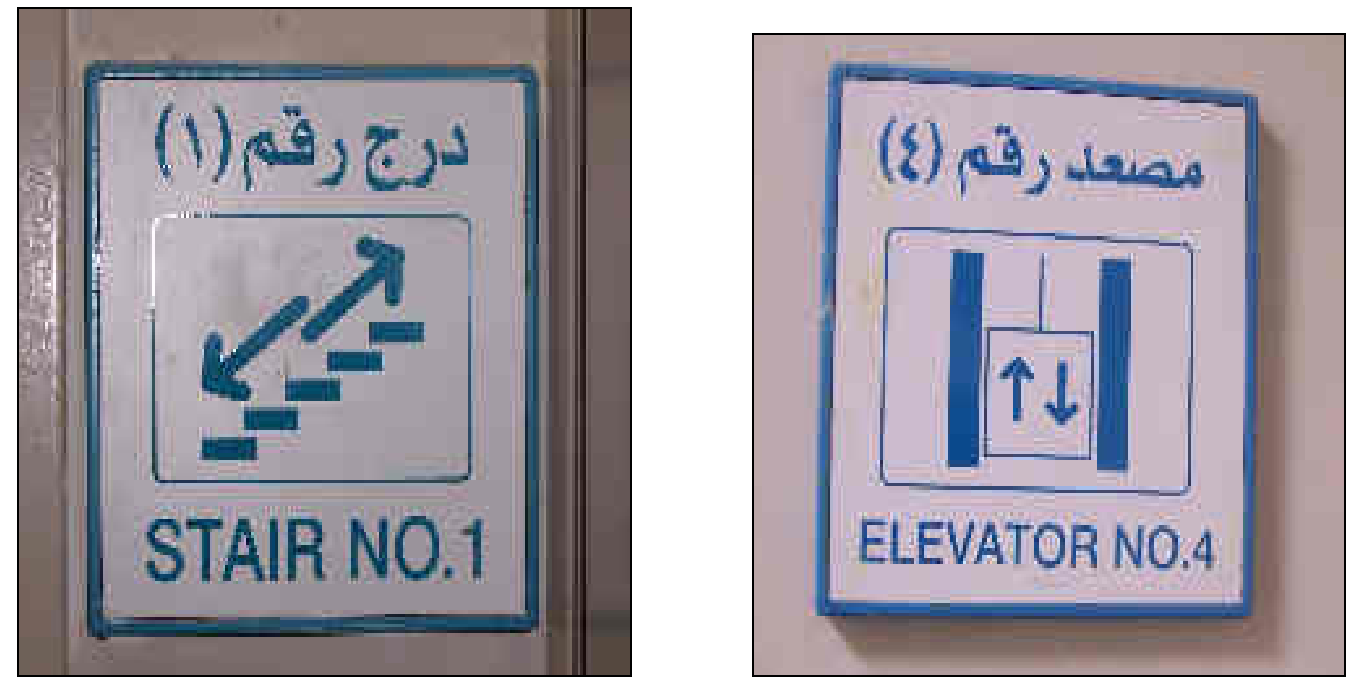

$$
\text { الثنكل رقم (30): يوضح أحد أنواع لوح الدرج الجدارية }
$$$$
\text { الثكل رقم (29): يوضح أحد أنواع لوح المصاعد }
$$

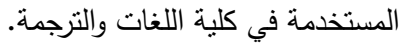
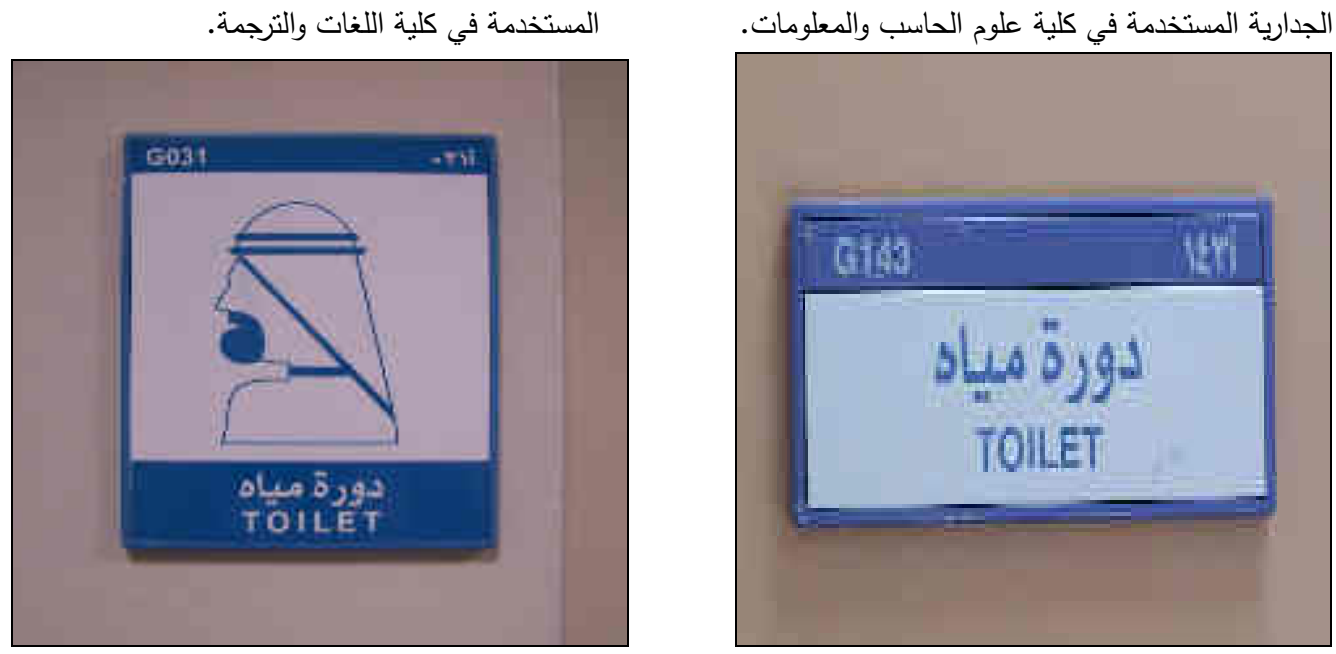

الثنكل رقم (32): يوضح نوع آخر من اللوح الجدارية المستخدمة للالالة على دورات المياه.

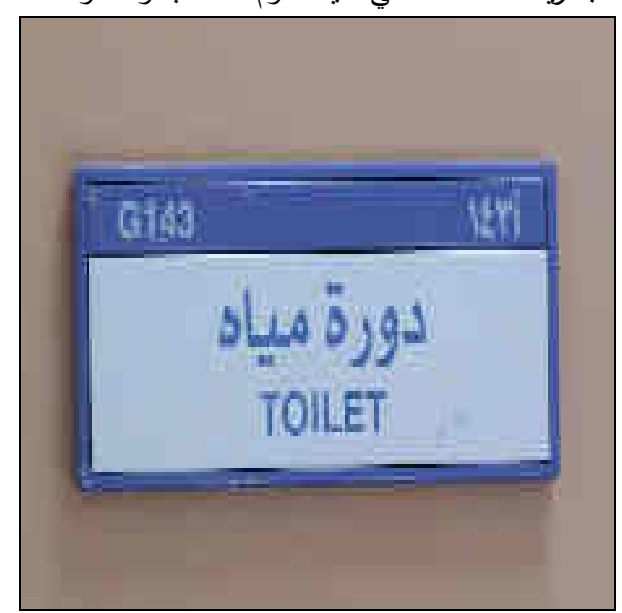

الثكل رقم (31): يوضح أحد اللوح الجدارية المستخدمة للالالة على دورات المياه.

\section{-10-8}

جميع الممرات ذات عروض نظامية نتراوح ما بين 2,40م و 340م ومغطاة ببلاط كسر رخام بأبعاد متفاونة، (انظر الجدول رقم 11). وغالبية المباني لا يوجد بممراتها عوائق مثل الأعمدة والعتبات وأحواض الزهور . وأهم

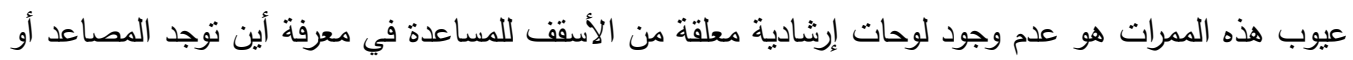
الارج أو دورة المياه، ..إلخ. 
الجدول رقم (11): يوضح الممرات الاخلية في كل كلية جديدة:

\begin{tabular}{|c|c|c|c|c|}
\hline $\begin{array}{c}\text { ملاحظات } \\
\text { م) }\end{array}$ & مواد الإنهاء & $\begin{array}{c}\text { أكبر عزض (م) } \\
\text { (م) }\end{array}$ & $\begin{array}{c}\text { أقل العرض } \\
\text { (م) }\end{array}$ & اسم الكلية \\
\hline 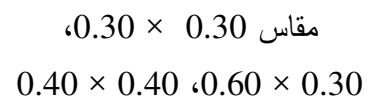 & كسر رخام & 3.40 & 2.40 & العــارة والتخطيط \\
\hline $\begin{array}{c}0.30,0.30 \text { × } 0.30 \text { × } 0.60 \text { × } 0.40 \text { × } 0.40 \\
0.40\end{array}$ & كسر رخام & 3.40 & 2.40 & علوم الحاسب والمعلومات \\
\hline $\begin{array}{c}0.30,0.30 \text { × } 0.30 \text { × } 0.30 \text { × } 0.40 \text { × } 0.40 \\
0.40\end{array}$ & كسر رخام & 3.40 & 2.40 & العلوم الطبية التطبيقية \\
\hline $\begin{array}{c}0.30, \text { × } 0.30 \text { مقاس } 0.40 \\
0.40 \text { × }\end{array}$ & كسر رخام & 3.40 & 2.40 & اللغات والترجمـة \\
\hline
\end{tabular}

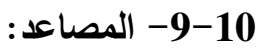

جميع المباني بها مصاعد نظامية ولكن معظمها بعيدة عن المداخل. فيما يخص أعدادها فهي أقل مما يتطلبه النظام، حيث بلغت نسبة النقص قرابة 37,5\% (انظر الجدول رقم 12 و الأشكال من الأرقام 33 إلى 36).

الجدول رقم (12): يوضح أعداد المصاعد وأبعادها:

\begin{tabular}{|c|c|c|c|c|c|c|}
\hline ملاحظات & $\begin{array}{c}\text { فتحة الباب } \\
\text { (م) }\end{array}$ & العرض & $\begin{array}{c}\text { الطول } \\
\text { (م) }\end{array}$ & العنفذ & المطلوب & اسم المشروع \\
\hline بعيدة عن المداخل & 1.0 & 1.60 & 1.70 & 4 & 5 & العــارة والتخطيط \\
\hline بعيدة عن المداخل & 1.0 & 1.60 & 1.70 & 5 & 8 & علوم الحاسب والمطلومات \\
\hline بعيدة عن الدداخل & 1.0 & 1.60 & 1.70 & 4 & 7 & العلوم الطبية التطبيقيـة \\
\hline \multirow[t]{2}{*}{ قريبة من الدداخل } & 1.0 & 1.60 & 1.70 & 2 & 4 & اللغات والترجمــة \\
\hline & & & & 15 & 24 & المجموع \\
\hline
\end{tabular}

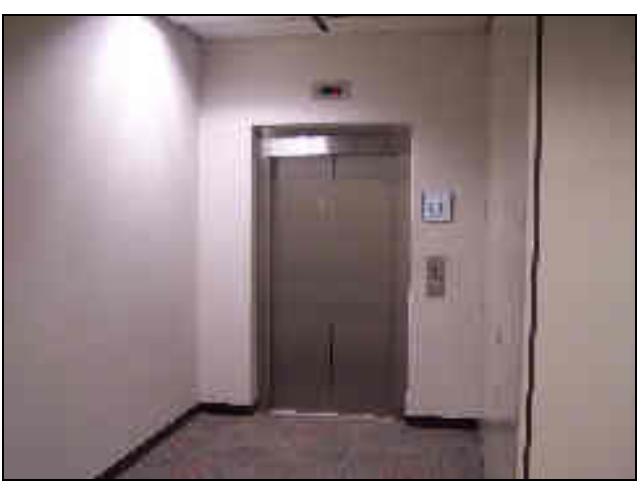

الثكل رقم (34): يوضح نوعية مصاعد كلية علوم الحاسب والمعلومات.

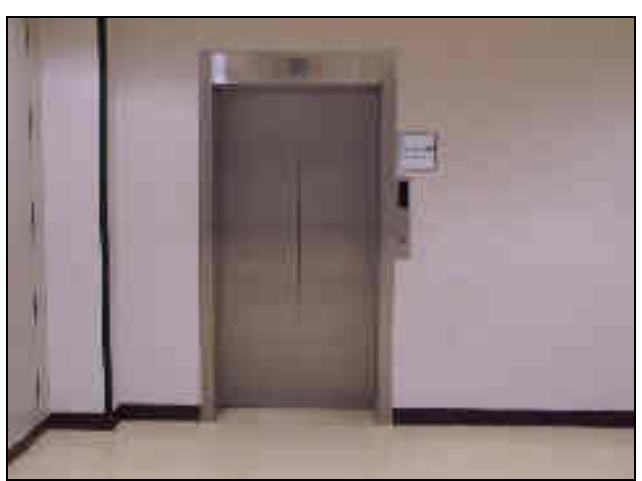

الثكل رقم (33): يوضح نوعية مصاعد كلية العمارة والتخطبط. 


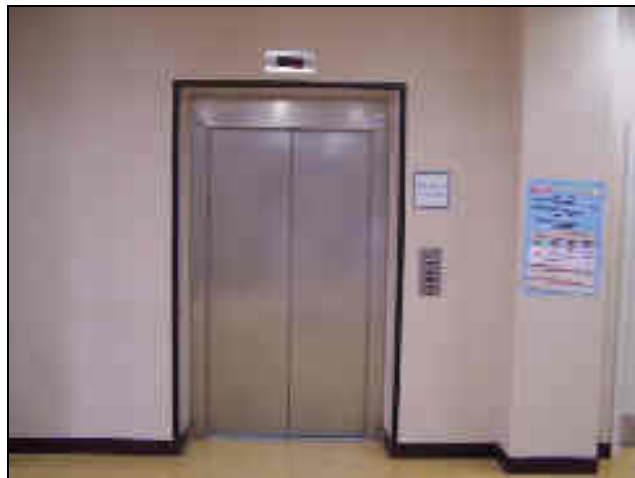

الثكل رقم (36): يوضح نوعية مصاعد كلية اللغات

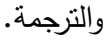

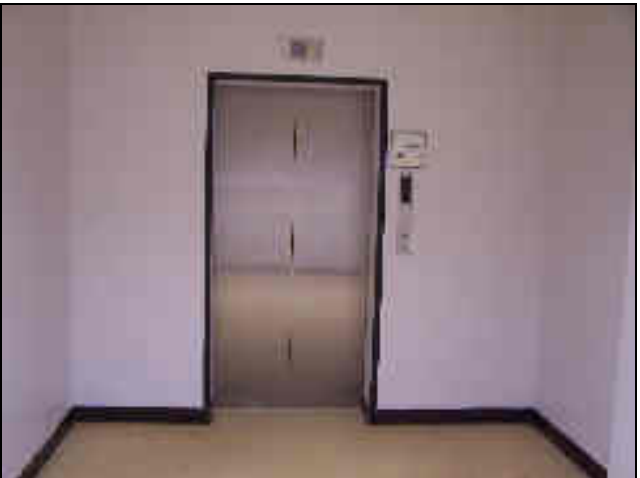

الثكل رقم (35): يوضـح نوعية مصاعد كلية العلوم الطبية التطبيقية.

10-10

في الواقع كلية العمارة والتخطيط هي الكلية الوحيدة التي بها دورات مياه للمعوقين نظامية بحيث يمكنه استخدامها بكل بسر وسهولة، بينما الكليات الثلاث الباقية دورات المياه بها لا يمكن للمعاق أن بيتخدمها لأحد

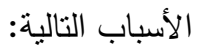

• تجهيزاتها ناقصة كما في كلية اللغات والترجمة وكلية علوم الحاسب والمعلومات (انظر الشكل رقم

• مساحة الدورة أقل من الحد الأدنى (20.20م) كما في كلية اللغات والترجمة (انظر الثكل رقم 38). بدون مغسلة كما في كلية علوم الحاسب والمعلومات (انظر الثكلين رقم 39 و 40).

بعض دورات المياه ليس بها دورة خاصة لاستخدام المعوقين، حيث بلغ نسبة النقص قرابة 43\%. كذلك فإن أبواب دورات المعوقين في كلية اللغات والترجمة هي الوحيدة النظامية حيث تقتح للخارج بينما باقي الكليات دورات المعوقين بها تفتح للاخل (أنظر الثكلين رقم 41، و 42). الجدول رقم (13): دورات المياه:

\begin{tabular}{|c|c|c|c|c|c|c|}
\hline الجاب فتح & عرض باب & (لعرض & $\begin{array}{c}\text { (م) } \\
\text { (مول }\end{array}$ & العنفذ & المطلوب & اسم المشروع \\
\hline للاخل & 0.85 & 1.40 & 2.40 & 12 & 24 & العمـارة والتخطيط \\
\hline للاخل & 0.85 & 1.40 & 2.40 & 9 & 24 & علوم الحاسب والمعلومات \\
\hline ل للاخل & 0.85 & 1.40 & 2.40 & 15 & 21 & العلوم الطبية التطبيقية \\
\hline \multirow[t]{2}{*}{ للخارج } & 0.80 & 1.15 & 1.80 & $\overline{99}$ & 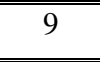 & اللغات والتترجمـة \\
\hline & & & & 45 & 78 & المجموع \\
\hline
\end{tabular}




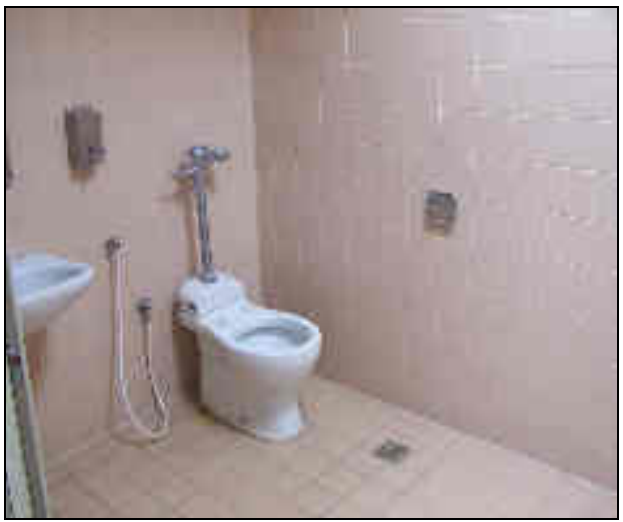

الثكل رقم (38): يوضح فرش أحد دورات المياه الناقص بكلية علوم الحاسب والمعلومات.

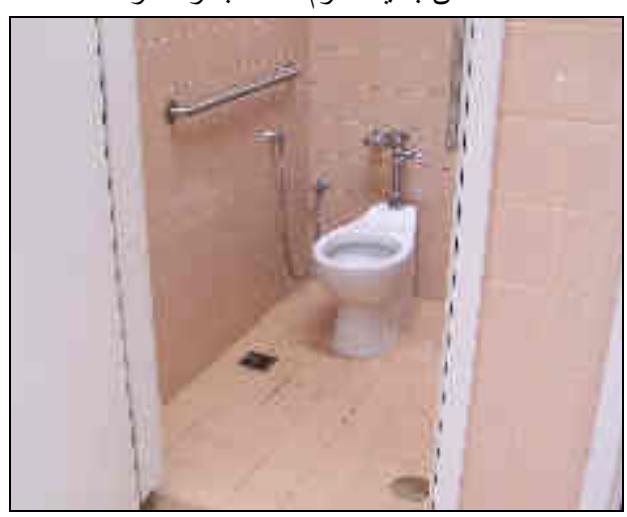

الثكل رقم (40): يوضح فرش أحد دورات المياه الناقص بكلية اللغات والتزجمة.

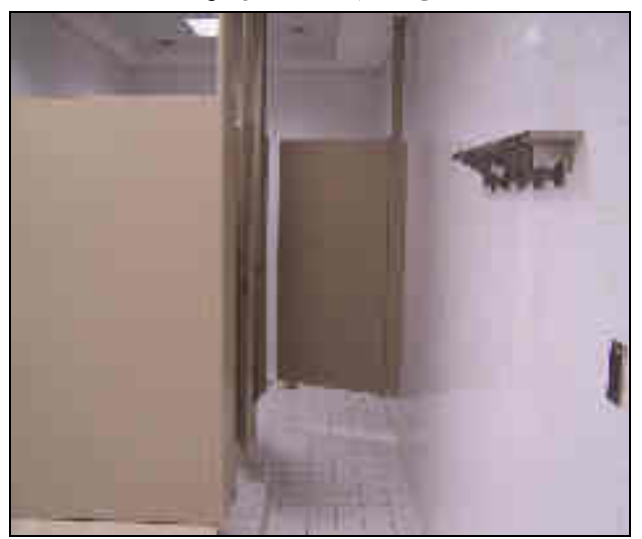

الثكل رقم (42): باب غير نظامي يفتح إلى الداخل.

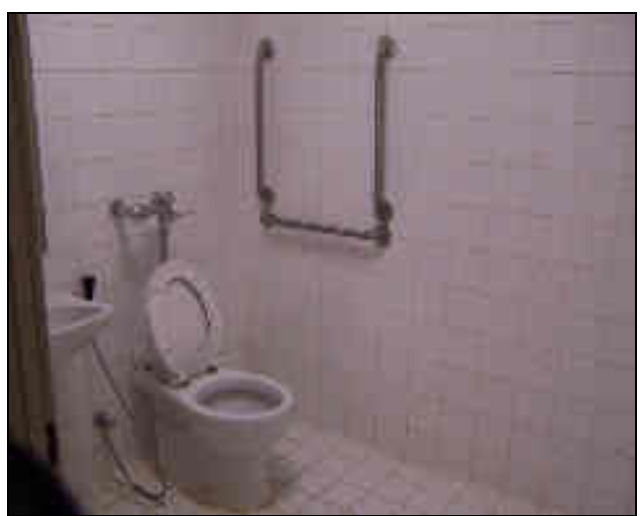

الثكل رقم (37): يوضح أحد دورات المباه النظامية بكلية العمارة والتخطيط.

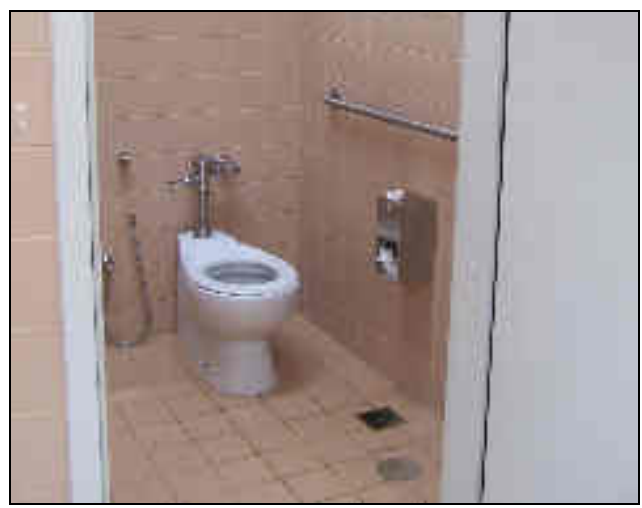

الثكل رقم (39): يوضح فرش أحد دورات المياه

الناقص بكلية العلوم الطبية النطبيقية.

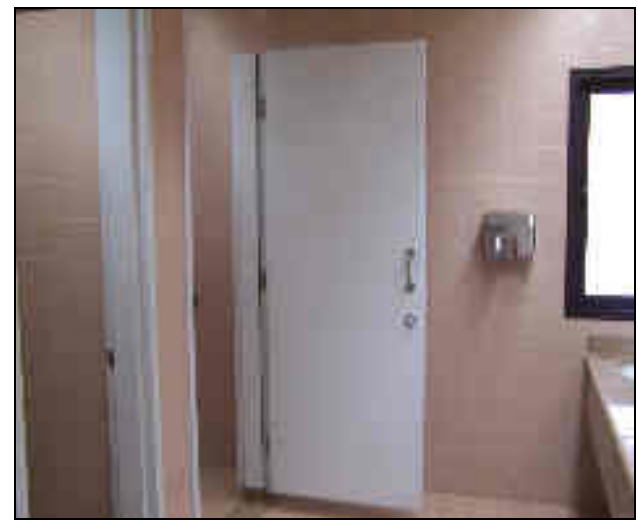

الثكل رقم (41): أحد الأبواب النظامية التي تفتح للخارج. 
من خلال الإطلاع على أسماء المصممين لمباني الكليات الأربع قيد البحث نجد أنه بالرغم من تصميم بعض كبار المعماريين العالميين لمباني بعض هذه الكليات - كما مبنى كلية العمارة والتخطيط الذي صمم من قبل المعماري كنزو تانج (Kenzo Tange) - فإنه لا يوجد مبنى واحد من ضمن العينة مؤهلاً بالكامل للاستخدام

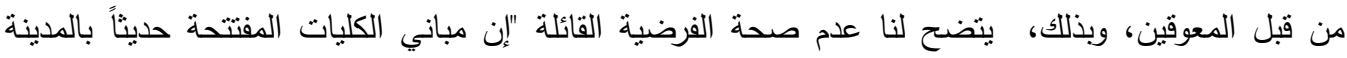
الجامعية لجامعة الملك سعود والمصممة من قبل معماريين مشهورين سعوديين أو غير سعوديين والمراجعة والمعتدة من وكالة الجامعة للمشاريع؛ هي في الغالب شاملة الانشتراطات الخاصة بالمعوقين والمعتمدة في كتيب "الاثتراطات الخاصة بالخدمات البلاية المتعلقة بالمعاقين". أما عن أسباب عدم تأهيل تلاك المباني لاستخدام المعوقين فإنه لا يمكن إرجاعه لأسباب مادية لأن تكلفة تلكائ المباني تجاوزت مئات الملايين من الريالات، والمبلغ المطلوب لتأهيل تلاك المباني لكي يمكن استخدامه من التاني

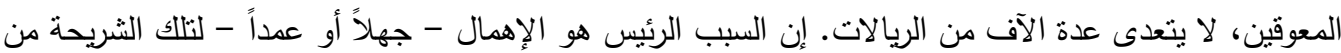

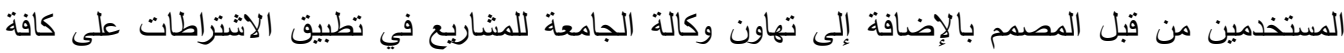
المباني المختلفة داخل المدينة الجامعية لجامعة الملك سعود.

$$
\text { 10-10-12- التوصيات: يوصي الباحث بما يلي: }
$$

رفع الوعي لدى طلاب العمارة بالكليات والأقسام المختلفة بالمملكة عن الاشتراطات الخاصة بالمعوقين عن طريق تطبيق تلاك الاشتراطات على المشاريع المختلفة التي تطرح بمقرات التصميم المعماري.

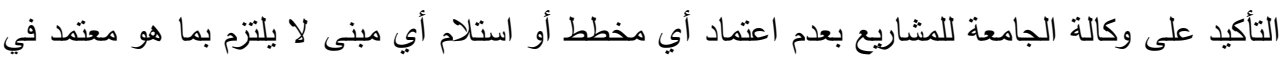

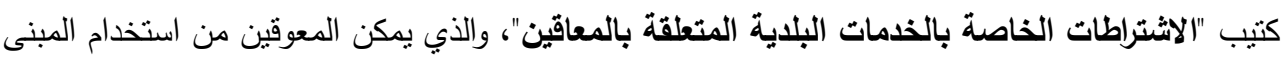

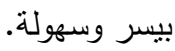
إنثاء إدارة خاصة بالجامعة تقوم بوضع خطة زمنية يتم خلالها توفير الاشتراطات الخاصة بخدمات المعوقين الناقصة أو الغير نظامية في جميع الكليات والمباني الإدارية القديمة والحديثة بالحرم الجامعي. حث قسم المرور بإدارة السلامة والأمن الجامعي على مخالفة وتغريم من يستخدم مواقف السيارات المخصصة للمعوقين ووضع غرامات كبيرة رادعة.

\section{المراجع}

[1] التقرير السنوي (1419 - 1420هـ). وزارة العمل والثؤون الاجماعية، وكالة الوزارة للشؤون الاجتماعية، الرياض، 1420هـ. [2] كتيب الاشتراطات الخاصة بالخدمات البلدية المتعلقة بالمعوقين. وزارة الثؤون القروية والبلدية، وكالة الوزارة للثنؤون الفنية، الرياض، 1412هـ. 
[3] الحازمي، محسن بن علي. البحث الوطني لدراستة الإعاقة لدى الأطفال بالمملكة العربية السعودية (17)

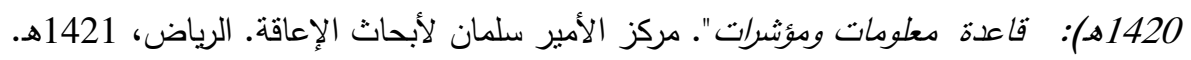

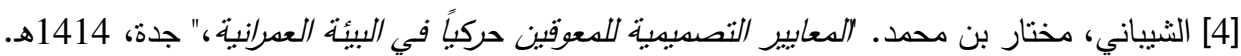

[5] UN Resolutions: 3447, Declaration on the Rights Of Disabled Persons General Assembly A/34Addl 21 No. 1979, 1975.

[6] Goldsmith S., Rea P "A Symbol for disabled People", Symboapplication manual, RIBA, London, 1969.

[7] الورع، مأمون بدر الدين. "التصديم للمعوقين - متطلبات البيئة الخارجية، ، سجل أوراق ندوة نقل المعوقين

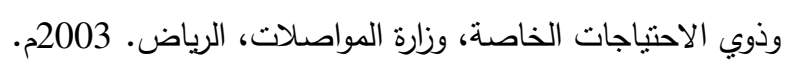

[8] Goldsmith, S., "Designing For the Disabled", Third ed, RIBA publications Ltd, England, 1976, P 23.

[9] Jencks, Charles, "The Language of Post-Modern Architecture - Rizzli,1977.

[10] Raymond, Lifchez, and Winslow, Barbara. "Rethinking architecture: design students and physically disabled people", university of California press,1987, p9.

[11] CIS, The International Council for Building Research and Studies and Documentation "Functional Requiremental report, The Third Congress Copenhagen, 1965, pp. 379-383.

[12] المعايطـة، داود محمود. " تجهيزات الدباني والأماكن الدفتوحـة،" سـل أوراق ندوة نقل المعوقين وذوي

$$
\text { الاحنياجات الخاصة، وزارة المواصلات، الرياض. 2003 2003. }
$$

[13] Cope, J. G., and Allred, L. J. "Community intervention to deter illegal parking in spaces reserved for the physically disable", Journal of Applied Behavior Analysis, 24(4), 1991, pp 687-693.

[14] Cope, John G. "Controlling Illegal Parking in Spaces Reserved for the Physically Disabled", Environment and Behavior, Vol. 27, No. 3, 1995, pp 317-327. 


\section{الملاحق}

ملحق رقم (1): غلاف الكتيب ويعض الاشتراطات والمعايير الفنية المنثورة به والتي ركز عليها البحث 


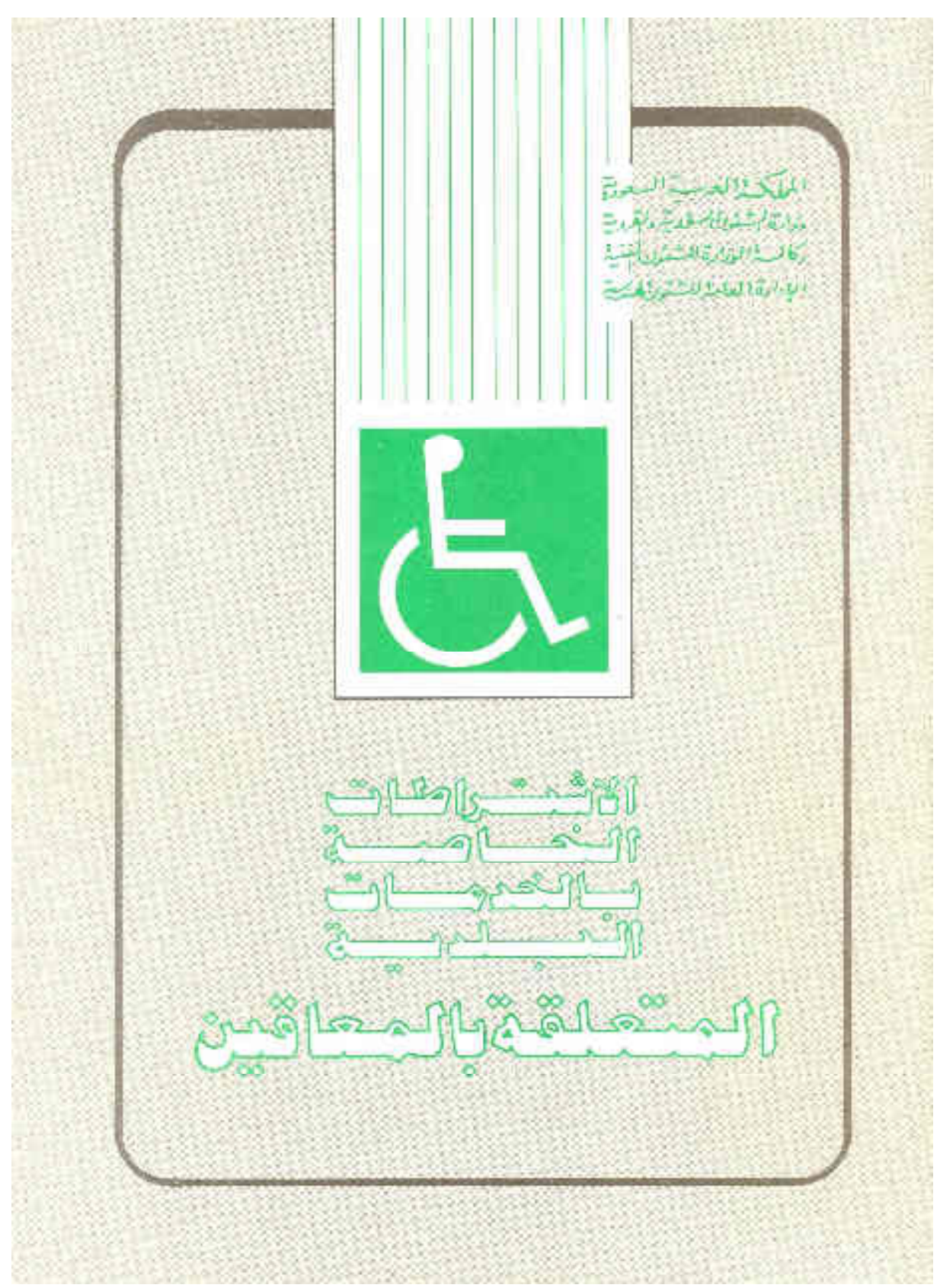

الاشتراطات والمعايير الفتية

تتمثل مشكلة المعاق في الحركة والتتقل من مكان لآخر إذ يعتمد في معظم الحالات على الأجهزة المساعدة

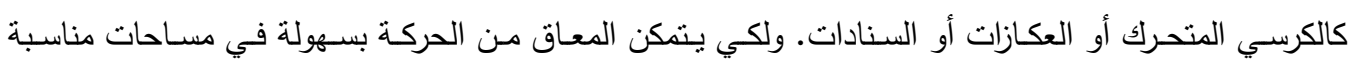


بالأمـاكن والمبـاني العامـة والخاصـة كالـدوائر الحكوميـة والأسـواق والمسـاجد والحـدائق العامـة والمبـاني التعليميـة والترفيهية ومباني الخدمات وغيرها من المباني التي قد يتردد عليها المعاق فإن الأمر يتطلب تحقيق الاشتراطات والمعايير الفنية المتعلقة بالخدمات المتواجدة في تلك الأماكن من حيث أوضاعها وأبعادها والفراغات المطلوبة.

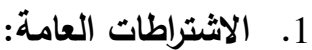

على البلديـة الالتزام بتلك الاشـتراطات في مشـاريعها وكذلك أخذها في الاعتبـار قبـل الترخيص للمشـاريع الخاصة لأهميتها في مساعدة المعاق على الحركة والتتقل بسهولة، وهى تتحصر بصورة عامة في الخدمات المتواجدة خـارج المبـاني كالثـوارع والأرصفة وممـرات المشـاة ومداخل المبـاني والأمساكن ومواقف السـيارات ودورات المياه العامة، .. الخ، وتبعاً للاعتبارات التالية:

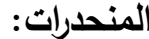

هي عبارة عن أسطح مائلة تتفذ من مواد خشنة لمنع الانزلاق. وتكون درجة الميل بحد أقصى (1 : 8) ولا يقل عن (1 : 12) وذلك في مداخل المباني ومخـارج الطوارئ والأرصفة والممرات والمستويات المختلفة التي تتغير مناسيبها. وتكون وفقاً للضوابط التالية

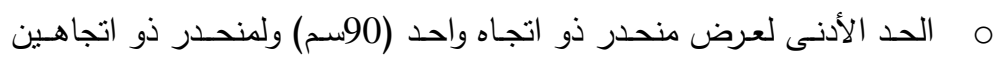

O يثبت درابزين بارتفاع لا يقل عن (85سم) ولا يزيد عن (100سم) على جانبي

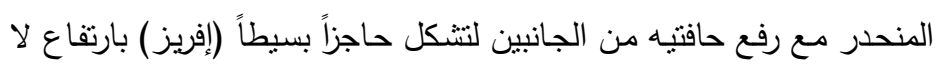

يقل عن (8سم) من سطح المنحدر لتوفير الحماية والتقليل من المخاطر .

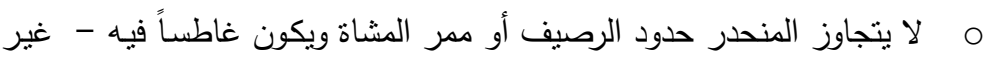
بارز - ويشار إليه بلوحات إرشادية مميزة. ويكون ضمن منطقة عبور المشاة.

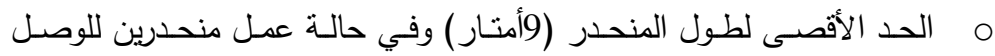
لارتفاع ما بلزم الفصل بينهما بسطح مستو (بسطه) لا يقل عن (180سم).

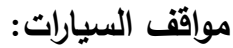

م تخصص مواقف لسيارات المعاقين في جميع مواقف السيارات العامـة والخاصـة وفي أماكن مناسبة يسهل الوصول منها وإليها ويكون ذلك أقرب ما يكون من مون مداخل ومخارج الأماكن التي يرتادها المعاقون. أن تميز المواقف الخاصة بالمعاقين وذللك باستخدام الشعار الخاص بهم. وألا تقل نسبة مواقف سيارات المعاقين عن (5\%) من المواقف العامة وبحد أدني بادي 
م ألا تقل المساحة المخصصة لسيارة المعاق عن (25م2).

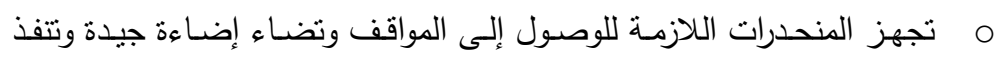

أقرب ما يكون إلى مواقف سيارات المعاقين.

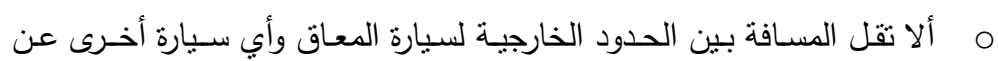

$$
\text { (160) }
$$

\section{ممرات المشاة والأرصفة: ويشترط فيها مل يلي:}

م أن تكونه خالية من العوائق والبروزات وأرضيتها من مواد خشنة لـنع الانزلاق

$$
\text { وتزود بالمنحدرات اللازمة واللوحات الإرشادية المميزة. }
$$

م عدم وضع أغطية الصرف التمديدات في أرضيات المرات والأردات الأرصفة وإذا كان

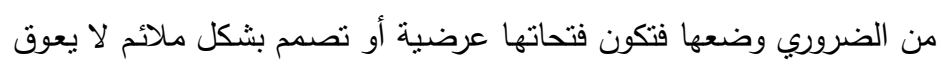
مستخدمي الكراسي المتحركة.

مراعاة ألا تكون ممرات المشاة بالأرصفة قريبة من الحوائط الخارجية للمباني

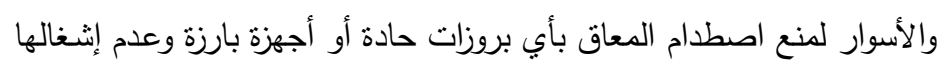
بأية عوائق أخرى تؤدي إلى عرقلة المعاق وإصابته.

\section{دورات المياه العامة وإلحمامات:}

عند تصميم دورات المياه في الأمـاكن والمباني العامـة يراعى تخصيص جزء منهـا لخدمة المعاقين بواقع دوره واحدة للرجال وأخرى للنساء وفقاً لما ليلي :

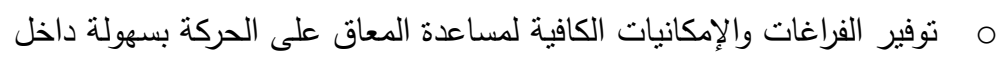

$$
\text { وخارج الدورة. }
$$

م تفتح أبواب الدورة الخاصة بالمعاق للخارج ولا يقل عرض الباب عن (82سم)

$$
\text { ويرتفع عن سطح الأرض مسافة (20سم). }
$$

م تثبت الأحواض وأدوات التحكم والملحقات الخاصة بالدورة كالمناشف وحامل

الورق وخلافه على ارتفاع لا يقل عن (76سم) ولا يزيد عن (137سم).

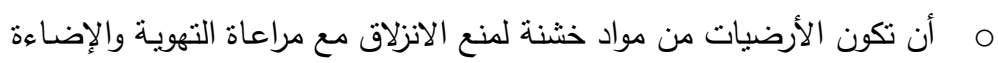

$$
\text { الجيدة. }
$$

م أن يراعى تزويد المبنى المتعدد الأدوار بدورة مياه خاصـة بالمعاقين بكل دور

$$
\text { بوجد به دورات مياه مجمعة. }
$$

م الحد الأدنى لمساحة الحمام (20.20م2). 
على البلديـة تـوفير الاشتراطات الخاصـة الضـرورية بالتعـاون مـع الجهات الحكوميـة التي تتعلق خدماتها

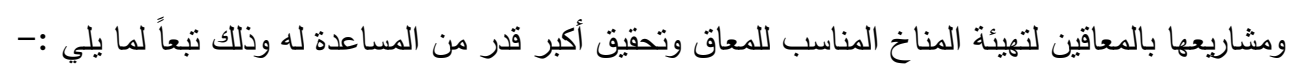

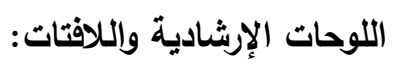

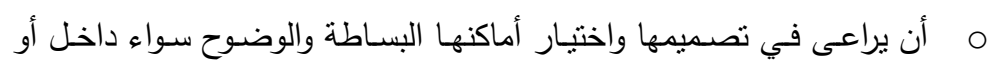

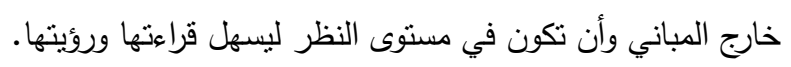

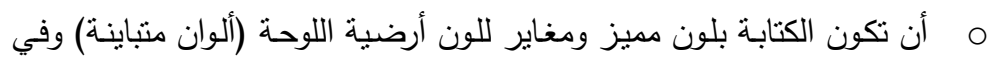

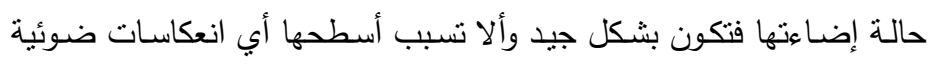
من شأنها إعاقة الروية والقراءة.

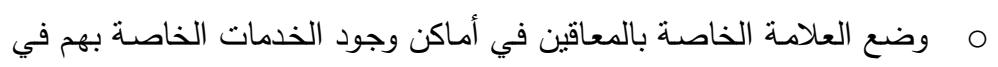
المباني العامة والخاصة والمرافق العامة.

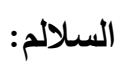

تكون السـلالم في المباني التي يرتادها المعاقون أو التي يعلون بها وفقاً للمنطلبات

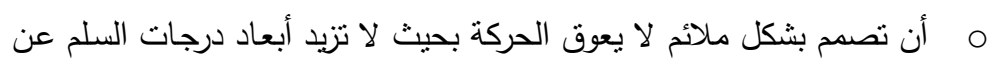

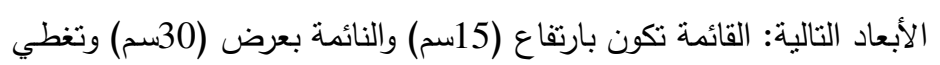

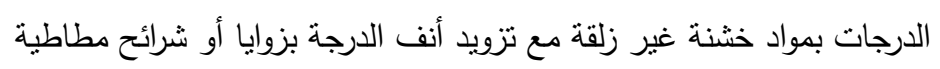
طولية لمنع الانزلاق أو أية مواد أخرى تؤدبي نفس الغرض.

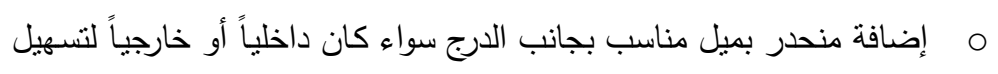
حركة المعاق كل حسب حالته. م يزود الدرج بدرابزين على الجانبين بارتفاع لا يقل عن (85هم) ولا يزيد عن الهن

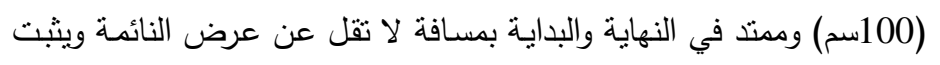
جيداً. م تزود المباني متعددة الأدوار بسالم ووسائل الهروب اللازمة ومخارج الطوارئ مع مراعاة المساحات والأبعاد الخاصة بتلك العناصر .

\section{الأبواب:}

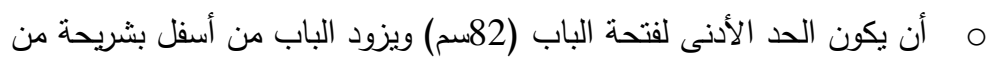

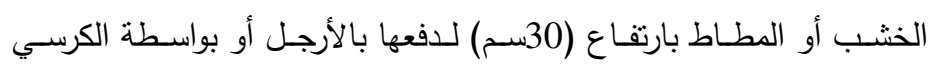

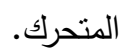


م أن تزود الأبواب ذات المسطحات الزجاجية بالكامل بعلامات واضحة ملونـة

$$
\text { في مستوى النظر لتمييزها وتجنب الاصطدام بها. }
$$

م أن تزود الأبواب المصمتة بفتحات (نظارات) زجاجية وبمساحات مناسبة تمكن ونابن

$$
\text { من الروية الواضحة. }
$$

م تثبت المقابض والكوالين وخلافه على ارتفاع لا يقل عن (76سم) ولا يزيد عن (137سم) من سطح الأرض ويراعى فيها البساطة وسهولة الاستعمال والشكل

م أبواب الطوارئ تفتح للخارج مع عمل المنحدرات اللازمة. o استخدام الأبواب الإكترونية كلما أمكن وذلك في الأماكن العامـة التي يتردد عليها المعاقين.

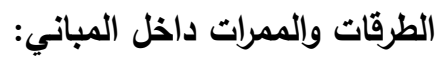

م تزود بكافـة الخدمات اللازمـة من درابزينـات ومقابض وأدوات تحكم ووسـائل سمعية وبصرية وغيرها كما تزود الإضـاءة الكافية الصحية ووسائل الإعلام الواضحة.

م مراعـاة عدم وجـود عوائق بالطرقـات والممـرات كالأعمدة والعتبـات وأجهـزة

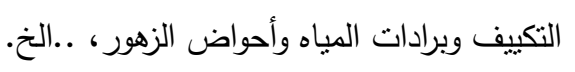

O تكسية الأرضيات بمواد خشنة غير زلقة. م لا يقل عرض الممر عن (137سم).

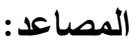

o تستخدم المصاعد في المباني التي يزيد ارتقاعها عن دورين (أرضي +

(أول).

O ميراعـى عنـد اختيـار المصــاعد مناسـبة حجمهـا وحمولتهـا ونوعيتهـا وملائمتهـا لاحتياجـات مسـتعمليها مـن المعـاقين وتزوبـدها بالإضـاءة والتهوية الكافية. م توفر مساحة كافية أمسام باب المصعد لا تقل أبعادها عن (150سم × 150سـ) بكل دور ويكون موقع المصسعد قريباً من المداخل الرئيسية للمباني وسهل الوصول إليه. 
م الحـــ الأدنـى لمسـاحة الصـاعدة (الكابينـة) التـي تسـتوعب الكراسـي

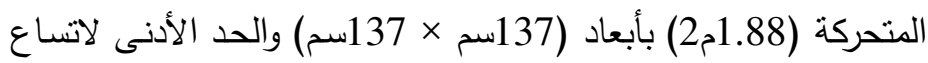

فتحة باب المصعد (82سم).

م تكون أرضية المصعد من مواد خشنة وتزود الكابينة بالقوائم والدرابزينات

والحواجز والمقابض والإثشارات الضوئية والصوتية اللازمة.

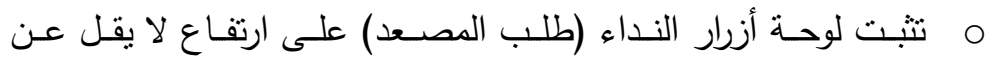

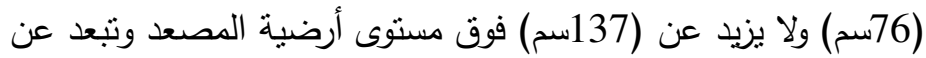

الحائط الجانبي مسافة (40سم) وتضاء اللوحة إضاءة جيدة.

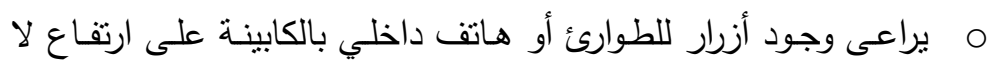

$$
\text { يقل عن (76سم) ولا يزيد عن (137سم). }
$$

ملحق رقم (2): بعض أنواع اللوحات الإرشادية الخارجية الواجب توفرها
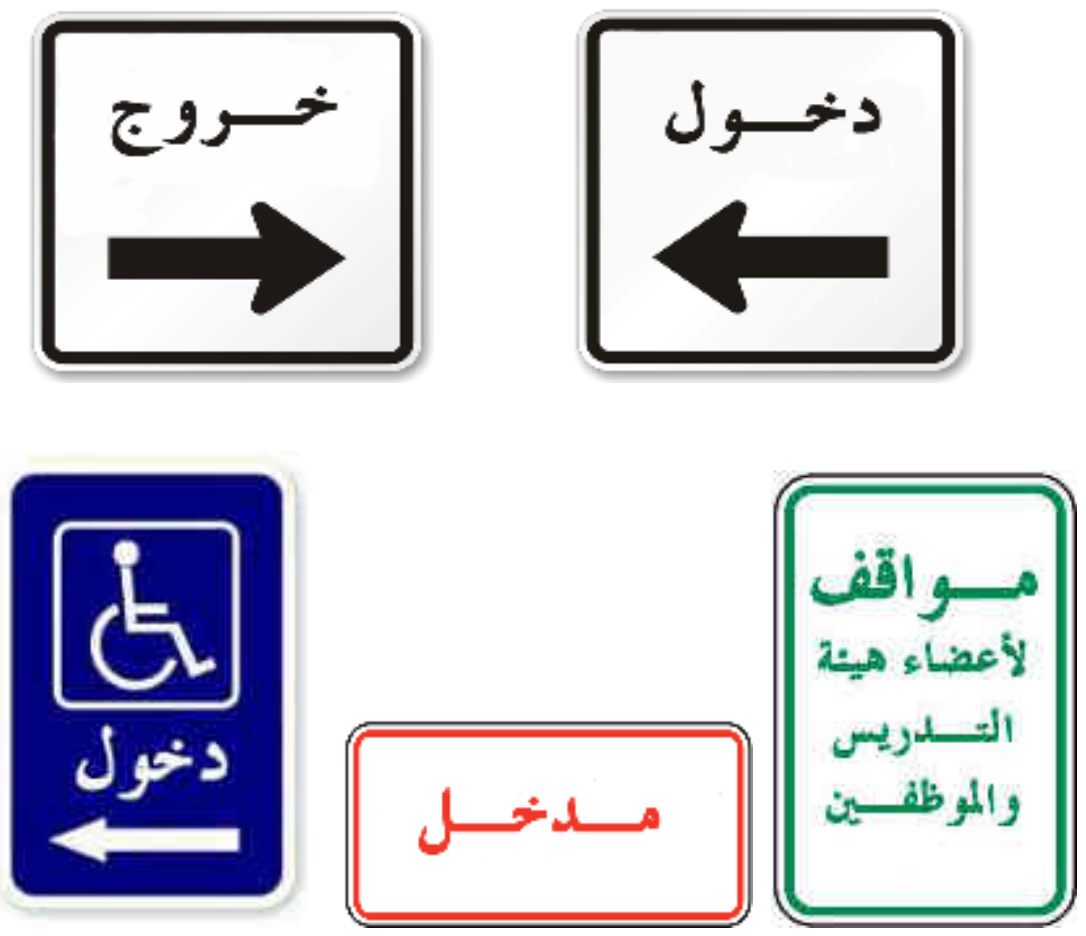

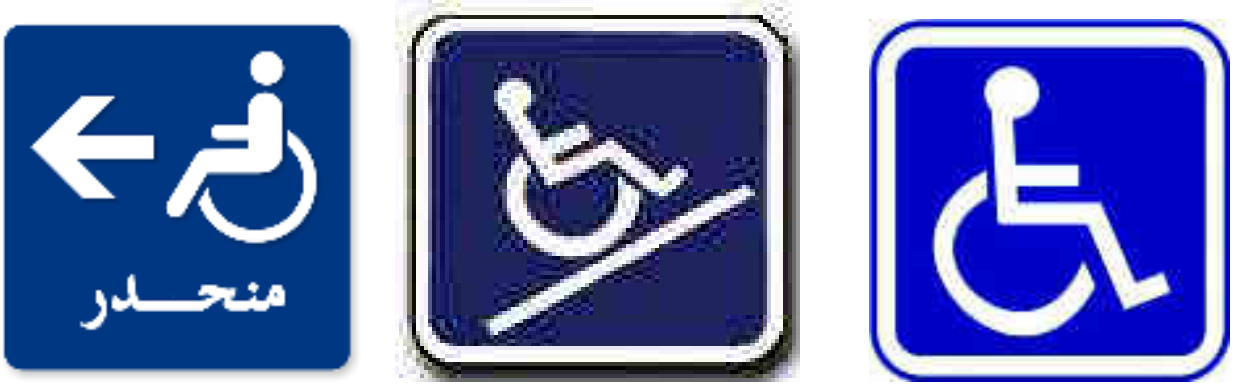

ملحق رقم (3): بعض أنواع اللوحات الإرشادية الداخلية الواجب توفرها
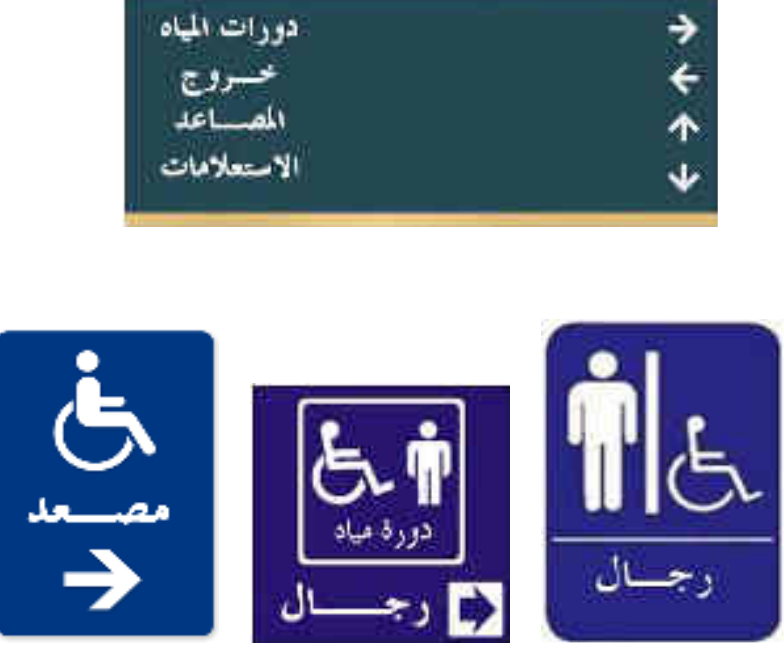

$\rightarrow$
$\leftarrow$
$\downarrow$

\section{个文}

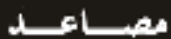
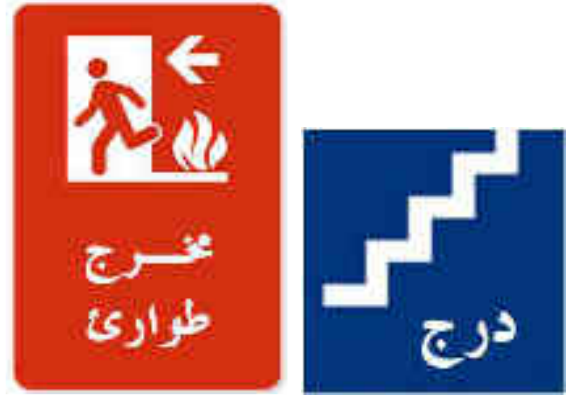

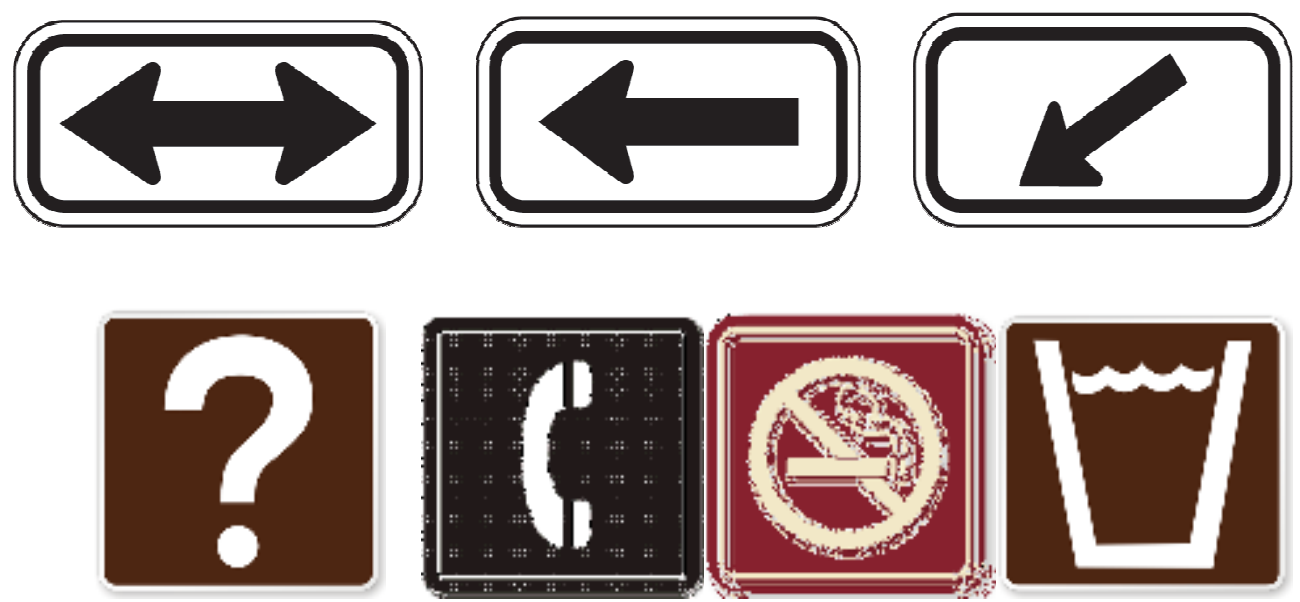